\title{
BANK BEHAVIOR AND THE COST CHANNEL OF MONETARY TRANSMISSION
}

\author{
OLIVER HUELSEWIG \\ ERIC MAYER \\ TIMO WOLLMERSHAEUSER
}

CESIFO WORKING PAPER NO. 1813

CATEgory 6: Monetary Policy and InTERnAtional FinAnCE

SEPTEMBER 2006

An electronic version of the paper may be downloaded

- from the SSRN website:

- from the RePEc website:

www.SSRN.com

- from the CESifo website:

www.RePEc.org

www.CESifo-group.de 


\title{
BANK BEHAVIOR AND THE COST CHANNEL OF MONETARY TRANSMISSION
}

\begin{abstract}
This paper presents a New Keynesian model that dwells on the role of banks in the cost channel of monetary policy. Banks extend loans to firms in an environment of monopolistic competition by setting the loan rate according to a Calvo-type staggered price setting approach, which means that the adjustment of the aggregate loan rate to a monetary policy shock is sticky. We estimate the model for the Euro area by adopting a minimum distance approach. Our findings exhibit that, first, frictions on the loan market influence the propagation of monetary policy shocks as the pass-through of a change in the money market rate to the loan rate is incomplete, and, second, the cost channel is operating, but the effect is weak since inflation is driven by real unit labor costs rather than the loan rate. Our main conclusion is that the strength of the cost channel is mitigated as banks shelter firms from monetary policy shocks by smoothing lending rates.
\end{abstract}

JEL Code: E44, E52, E58.

Keywords: bank behavior, cost channel, minimum distance estimation.

Oliver Hülsewig
Ifo Institute for Economic Research at
the University of Munich
Poschingerstr. 5
Germany -81679 Munich
Huelsewig@ifo.de

Timo Wollmershäuser

Ifo Institute for Economic Research at

the University of Munich

Poschingerstr. 5

Germany-81679 Munich

Wollmershaeuser@ifo.de

September 15, 2006

We are grateful to Helge Berger, Steffen Henzel, Oliver Holtemöller, Martin Kukuk, and Klaus Wälde for valuable comments and suggestions. In addition we benefitted from the reactions of the participants at the Royal Economic Society Annual Conference, the European Meeting of the Econometric Society, the ZEI\{Summer School 2006 on Monetary Theory and Policy, the Verein für Socialpolitik Annual Meeting, the Annual Conference of The Money, Macro and Finance Research Group, and internal research seminars at the Universities of Aachen, Berlin and Würzburg. We also thank Alessandro Calza, Barbara Roffia and Silvia Scopel for kindly providing us the loan rate data. The usual disclaimer applies. 


\section{Introduction}

In the cost channel, banks play a pivotal role in the transmission of monetary policy, which stems from the notion that firms depend on credit to finance production (Barth and Ramey, 2000, Christiano, Eichenbaum, and Evans, 1997 and 2005, Chowdhury, Hoffmann and Scharbert, 2006, Rabanal, 2003, Ravenna and Walsh, 2006). Firms relate their pricing decision to credit conditions as their marginal production costs are directly affected by interest rates. Hence, a monetary contraction puts upward pressure on prices by deteriorating credit conditions through higher interest rates.

Christiano, Eichenbaum, and Evans (2005) and Ravenna and Walsh (2006) present a New Keynesian model that incorporates the cost channel besides the interest rate channel - i.e. the traditional aggregate demand channel - which states that prices decline immediately after a monetary contraction because of the procyclical drop in output and unit labor costs. As the cost channel is counteracting the interest rate channel, this implies that the reaction of prices to a monetary policy shock is mitigated, while the response of output is reinforced. Although, banks are considered in this framework explicitly, the scope of their behavior is limited as they only act as neutral conveyors of monetary policy actions.

This paper presents a New Keynesian model that dwells on the role of banks in the cost channel of monetary policy. Banks are assumed to extend loans to firms in an environment of monopolistic competition by setting the loan rate according to a Calvo-type staggered price setting approach. In this setup, only a random fraction of banks adjusts their loan rate to a change in the policy rate - that determines the marginal costs - while the remaining fraction leaves their loan rate unchanged, which means that the adjustment of the aggregate loan rate to a monetary policy shock is sticky. This is in contrast to Christiano, Eichenbaum, and Evans (1997, 2005) and Ravenna and Walsh (2006), who focus primarily on banks operating costlessly under perfect competition with the consequence that the loan rate always equals the policy rate.

Our motivation stems from the empirical finding for the Euro area that the pass-through from money market rates to loan rates is incomplete in the short- 
run (de Bondt, 2005). ${ }^{1}$ Using a vector autoregressive (VAR) model, we confirm this finding by showing that the adjustment of the loan rate to a monetary policy shock is delayed and less pronounced. The degree to which the reaction of loan rates to changes in money market rates is incomplete crucially depends on the structure of the financial system (Cottarelli and Kourelis, 1994).

Ehrmann et al. (2001) provide ample evidence for the Euro area that the degree of monopolistic competition in the loan market is high. Market imperfections can be explained by the existence of long-term relationships between banks and customers, which are typical for a bank-based financial system as opposed to a market-based financial system. ${ }^{2}$ In a customer market, the detachment of impersonal competitive forces is replaced by banker-customer relationships. Fried and Howitt (1980) and Berger and Udell (1992) argue that the benefit from bankercustomer relationships - that are predominately continuous - arises from banks offering an implicit interest rate insurance to risk-averse customers by keeping loan rates less variable than market rates. This means that loan rates are sticky with the consequence that the pass-through from changes in money market rates to loan rates is incomplete. Customers compensate the banks for bearing the risk of changing money market rates by accepting loan rates that are on average higher than market rates. In contrast, a market-based financial system is characterized by financial markets that prevail a relative high degree of competition with the consequence that the interest rate pass-through is more complete.

Following Barth and Ramey (2000) who show that after a restrictive monetary policy shock the price/wage ratio in many U.S. industries increases in a VAR, a number of studies have explored whether the cost channel is relevant for the transmission of monetary impulses. One strand of the literature uses partial equilibrium approaches by estimating single Phillips curve equations that account for a direct effect of the nominal interest rate on inflation. Ravenna and Walsh (2006) find supporting evidence for the existence of a cost channel in the U.S. Chowdhury, Hoffmann, and Schabert (2006) estimate Phillips curves for the G-7

\footnotetext{
${ }^{1}$ See also de Bondt (2005) for a comprehensive survey of the empirical findings reported in related work.

${ }^{2}$ As our model set-up below assumes that capital is constant and therefore abstains from the need to finance risky investment projects, more popular explanations for maintaining tight long-term relationships such as asymmetric information costs or switching costs cannot be used.
} 
countries and find that the cost channel is relevant in the U.S. and the U.K., but not in Germany and in Japan, which possibly indicates that the structure of the financial system - a market-based system versus a bank-based system - has an impact on the consequences of monetary policy actions. Another strand of the literature draws on general equilibrium approaches that account for both, the cost channel and the interest rate channel. Rabanal (2003) estimates his model for the U.S. and the Euro area using a Bayesian approach. Although his findings display that the cost channel is operating, the effect is quantitatively insignificant, which renders it irrelevant for monetary policymaking. Using a minimum distance estimation, Christiano, Eichenbaum, and Evans (2005) reach a similar conclusion for the U.S. and state that the role of the cost channel in their model is only minor.

Our paper belongs to the second strand of the literature. Following Rotemberg and Woodford (1998) and Christiano, Eichenbaum, and Evans (2005), we estimate our general equilibrium model for the Euro area by adopting a minimum distance approach, which matches the theoretical impulse responses to the empirical responses of an estimated VAR model to a monetary policy shock. Our results exhibit that (i) frictions on the loan market - and hence banker-customer relationships - play an important part in the propagation of monetary policy shocks as the reaction of loan rates to a change in money market rates is sluggish, and (ii) the cost channel is operating, but the effect is weak since the response of inflation to a monetary policy shock is dominated by the reaction of real unit labor costs rather than interest rates.

The main implication of our results is that the strength of the cost channel is mitigated as banks shelter firms from monetary policy shocks by smoothing lending rates. Even though firms base their pricing decision on credit conditions, the impact on inflation dynamics arising through changes in interest rates emerges as quantitatively unimportant.

The paper is structured as follows. In Section 2, the model is set out. While households and firms behave as in the standard New Keynesian framework with habit formation, sticky prices and rule-of-thumb price setters, an additional friction enters the model through the banking industry. Section 3 estimates the parameters of the model by using a minimum distance approach. In Section 
4 , the relevance of the structure of the banking system for the cost channel is discussed. Section 5 summarizes the main findings and concludes.

\section{The Model}

We present a New Keynesian model in which banks extent loans to firms by setting the loan rate in an environment of monopolistic competition according to a Calvo-type staggered price setting approach. The model builds on Gali, Gertler, and Lopez-Salido (2001), Christiano, Eichenbaum, and Evans (2005) and Ravenna and Walsh (2006), but yields richer implications for the evolution of the loan rate.

\subsection{Households}

There is a continuum of households, indexed by $j \in(0,1)$, deciding on consumption, labor supply, cash holdings and deposits. The $j$ th household maximizes its expected lifetime utility:

$$
E_{t-1} \sum_{i=0}^{\infty} \beta^{i} U_{j, t+i}
$$

where $E_{t-1}$ denotes the expectation operator, conditional on aggregate and household $j$ 's information up to - and including - time $t-1$, and $\beta \in(0,1)$ is a discount factor. ${ }^{3}$ Period utility $U_{j, t}$ is described by the following function:

$$
U_{j, t}=\xi_{t} \frac{\left(C_{j, t}-H_{t}\right)^{1-\sigma}}{1-\sigma}-\frac{\left(N_{j, t}\right)^{1+\eta}}{1+\eta}+\frac{\left(M_{j, t} / P_{t}\right)^{1-\nu}}{1-\nu},
$$

where $C_{j, t}$ is household $j$ 's consumption in period $t, \xi_{t}$ is a taste shock, $\sigma$ is the coefficient of relative risk aversion, $N_{j, t}$ is household $j$ 's labor supply, $\eta$ is the elasticity of marginal disutility of labor, $M_{j, t} / P_{t}$ are real cash balances, and $\nu$ is the elasticity of marginal utility of money. $H_{t}$ denotes an external habit variable which depends positively on consumption of the aggregate household sector in period $t-1, H_{t}=h C_{t-1}$.

\footnotetext{
${ }^{3}$ The assumption that the household's decisions for time $t$ and later are taken on the basis of the information set in time $t-1$ implies that decisions for time $t$ are predetermined. This is consistent with the identifying restrictions of the VAR model considered below, according to which output and inflation are prevented from responding contemporaneously to a monetary policy shock.
} 
Households maximize their expected lifetime utility (1) by choosing optimal consumption subject to an intertemporal budget constraint:

$$
P_{t} C_{j, t}+D_{j, t}+M_{j, t}=M_{j, t-1}+W_{t} N_{j, t}+R_{t-1}^{D} D_{j, t-1}+\Pi_{j, t}
$$

where $D_{j, t}$ are deposits hold at banks at the gross deposit rate $R_{t}^{D}, W_{t}$ is the nominal wage rate, and $\Pi_{j, t}$ are aggregate profits from the firms and banks distributed at the end of period $t$.

The relevant first-order conditions are:

$$
\begin{gathered}
E_{t-1} \lambda_{j, t}=\beta E_{t-1}\left(\lambda_{j, t+1} \frac{R_{t}^{D} P_{t}}{P_{t+1}}\right) \\
E_{t-1} \lambda_{j, t}=E_{t-1}\left[\xi_{t}\left(C_{j, t}-H_{t}\right)^{-\sigma}\right],
\end{gathered}
$$

where the Lagrange multiplier on the intertemporal budget constraint $\lambda_{j, t}$ denotes household $j$ 's marginal utility of consumption. We assume that financial markets are complete, and that households insure themselves against all idiosyncratic risk. Thus, households are homogeneous with respect to consumption and asset holdings, implying that the first-order conditions are equal for all households (Christiano, Eichenbaum, and Evans, 2005).

\section{$2.2 \quad$ Firms}

\subsubsection{Final Good Producers}

The final good $Y_{t}$ which is entirely used for consumption $C_{t}$ is produced by a continuum of wholesale producers in an environment of perfect competition. Final goods are bundles of differentiated goods $Y_{j, t}$ which are provided by a continuum of monopolistically competitive intermediate good producers. The technology to produce the aggregate final good is:

$$
Y_{t}=\left[\int_{0}^{1}\left(Y_{j, t}\right)^{\frac{\epsilon-1}{\epsilon}} d j\right]^{\frac{\epsilon}{\epsilon-1}},
$$

where $\epsilon>1$ governs the price elasticity of demand for the individual goods. The optimal allocation of households' expenditure across differentiated goods implies a downward sloping demand function:

$$
Y_{j, t}=\left(\frac{P_{j, t}}{P_{t}}\right)^{-\epsilon} Y_{t}, \text { for all } j \in(0,1),
$$


where $P_{j, t}$ denotes the price of good $Y_{j, t}$ and $P_{t}$ is the price index of final goods given by:

$$
P_{t}=\left[\int_{0}^{1}\left(P_{j, t}\right)^{1-\epsilon} d j\right]^{\frac{1}{1-\epsilon}}
$$

\subsubsection{Intermediate Good Producers}

Firms indexed by $j \in(0,1)$ produce a continuum of goods in monopolistically competitive markets. The production function of a firm is given by:

$$
Y_{j, t}=A_{t}\left(N_{j, t}\right)^{\alpha}
$$

where $N_{j, t}$ is employment, $\alpha$ is the output elasticity with respect to labor, and $A_{t}$ is an aggregate technology shock.

Firms face price frictions as in Calvo (1983), which implies a staggered price setting. The price level $P_{t}$ evolves each period as a weighted average of a fraction of firms $\theta$ that stick with last periods price level $P_{t-1}$ and a fraction of firms $1-\theta$ that are allowed to change prices:

$$
P_{t}^{1-\epsilon}=(1-\theta)\left(P_{t}^{*}\right)^{1-\epsilon}+\theta\left(P_{t-1}\right)^{1-\epsilon} .
$$

Prices that are reset in the current period $P_{t}^{*}$ can be decomposed into a component $1-\omega$ resulting from optimizing (forward-looking) firms and a component $\omega$ resulting from backward looking firms that follow a simple rule of thumb:

$$
P_{t}^{*}=\left(P_{t}^{f}\right)^{1-\omega}\left(P_{t}^{b}\right)^{\omega} .
$$

Gali, Gertler, and Lopez-Salido (2001) propose the following pricing scheme for backward looking firms:

$$
P_{t}^{b}=P_{t-1}^{*} \frac{P_{t-1}}{P_{t-2}}
$$

The fraction of forward-looking firms maximizes an intertemporal profit function:

$$
E_{t-1} \sum_{i=0}^{\infty} \theta^{i} \Delta_{i, t+i}, \Pi_{j, t+i}^{f}
$$

subject to households' aggregate demand given by equation (7). Share holders to which profits are redeemed discount cash flows in $i$ periods to come with a 
stochastic factor equal to $\theta^{i} \Delta_{i, t+i}$, where $\Delta_{i, t+i}$ denotes the intertemporal marginal rate of substitution of a representative household. Again we assume that pricing decisions occur prior to the realization of any aggregate time $t$ disturbance. Time $t+i$ profits by firm $j$ which reset prices at time $t$ are:

$$
\Pi_{j, t+i}^{f}=\left(P_{j, t}^{f}-\alpha P_{t+i} \varphi_{j, t+i}\right) Y_{j, t+i}
$$

where $\varphi_{j, t+i}$ are the real marginal cost. The solution to the optimization problem of the forward-looking intermediate firms can be shown to satisfy the following first-order condition:

$$
E_{t-1} \sum_{i=0}^{\infty} \theta^{i} \Delta_{i, t+i}\left[(1-\epsilon)+\epsilon \alpha \frac{P_{t+i}}{P_{j, t}^{f}} \varphi_{j, t+i}\right]\left(\frac{P_{j, t}^{f}}{P_{t+i}}\right)^{-\epsilon} Y_{t+i}=0
$$

where $P_{j, t}^{f}$ is the optimal price of forward-looking firm $j$.

The firm rents labor in perfectly competitive markets. Profits are distributed to households at the end of each period. As each firm is obliged to pay the wage bill in advance of production, it has to take up loans from a bank at the beginning of each period amounting to $W_{t} N_{j, t}$. Repayment by the firm occurs at the end of each period at the gross lending rate $R_{j, t}^{L}$. Production costs of firm $j$ are therefore given by $R_{j, t}^{L} W_{t} N_{j, t}$. Cost minimization implies that its real marginal costs at time $t+i$ are equal to:

$$
\varphi_{j, t+i}=\frac{1}{\alpha} R_{j, t+i}^{L} \frac{w_{t+i} N_{j, t+i}}{Y_{j, t+i}}=\frac{1}{\alpha} R_{j, t+i}^{L} S_{j, t+i},
$$

where $w_{t}=W_{t} / P_{t}$ is the real wage and $S_{j, t}$ are real unit labor costs. When the production is subject to diminishing returns to scale $(\alpha<1)$ and when firms maintain long-term business relationships with specific banks, firms with different production levels face different marginal costs. Relating $\varphi_{j, t+i}$ to average real marginal costs, $\varphi_{t+i}=\frac{1}{\alpha} R_{t+i}^{L} S_{t+i}$, yields

$$
\varphi_{j, t+i}=\varphi_{t+i}\left(\frac{P_{j, t}}{P_{t+i}}\right)^{\frac{\epsilon \zeta(\alpha-1)+\epsilon}{\alpha \zeta}}
$$

which is derived in detail in Appendix A. Note that $1 / \zeta$ measures the degree of monopoly power in the banking sector, and hence the importance of bankercustomer relationships. 


\subsection{Banks}

The individual bank $j$, which operates in an environment that is characterized by banker-customer relationships, faces the following loan demand function:

$$
L_{j, t}=\left(\frac{R_{j, t}^{L}}{R_{t}^{L}}\right)^{-\zeta} L_{t},
$$

where $\zeta>1$ is the interest rate elasticity of demand for the individual loan, and $R_{j, t}^{L}$ is the gross interest rate of the loan $L_{j, t}$ provided by bank $j$. This function is similar to the households' demand for goods. Unlike equation (7), however, the firms' demand for loans is postulated and not derived algebraically from microfounded behavior similar to the bundling approach described in Section 2.2.1. The reason for this is as follows. While the representative household's final consumption good is modeled as a bundle of differentiated intermediate goods, which is produced by perfectly competitive final good producers, a firm that depends on credit to finance production in a bank-based financial system is assumed to maintain a long-term relationship with a particular bank. In other words, the firm's credit portfolio is not diversified over all banks supplying loans in the market, so that the bundling approach is inapplicable. Notwithstanding this structural difference, which excludes the modeling of a "final loan sector", equation (18) is a loan demand function that applies to a customer market (Rotemberg and Woodford, 1991). In such a setting the parameter $\zeta$ can be interpreted as the firm's willingness to give up the business relationship with the bank in the event of changing loan rates. The higher $\zeta$, the looser become the ties between the bank and the customer and the more the structure of the loan market resembles perfect competition. ${ }^{4}$

Loan rate stickiness is introduced by assuming that banks operating in a customer market face nominal frictions as in Calvo (1983). Each bank resets its loan rate only with a probability $1-\tau$ each period, independently of the time elapsed since the last adjustment. Thus, each period a fraction $1-\tau$ of banks reset their loan rates, while a fraction $\tau$ keep their rates unchanged. The aggregate loan rate

\footnotetext{
${ }^{4}$ The interpretation of the price elasticity of demand for differentiated goods $\epsilon$ is different. As $\epsilon \rightarrow \infty$, the individual goods become closer and closer substitutes. The consequence, however, is the same as the market power of intermediate good producers diminshes.
} 
then satisfies:

$$
\left(R_{t}^{L}\right)^{1-\zeta}=(1-\tau)\left(R_{t}^{L *}\right)^{1-\zeta}+\tau\left(R_{t-1}^{L}\right)^{1-\zeta},
$$

where $R_{t}^{L *}$ is the newly set loan rate.

A bank that is able to reset in period $t$ chooses the loan rate so as to maximize the expected present value of its profit flow:

$$
E_{t} \sum_{i=0}^{\infty} \tau^{i} \Delta_{i, t+i} \Pi_{t+i}^{b a n k}
$$

As profits are redeemed to households at the end of each period, the stochastic discount factor equals the intertemporal marginal rate of substitution of a representative household. In contrast to households and firms, the optimization is conditional on the set of information available at time $t .{ }^{5}$ The banks grant loans to firms $L_{t}$, which are financed by deposits $D_{t}$ and central bank credits $B_{t}$. Time $t+i$ profit by bank $j$, which resets the loan rate in period $t$, is given by:

$$
\Pi_{j, t+i}^{\text {bank }}=R_{j, t}^{L} L_{j, t+i}-R_{t+i}^{D} D_{j, t+i}-R_{t+i}^{M} B_{j, t+i} .
$$

The central bank administers the policy rate $R_{t}^{M}$, which determines the interest rate on the interbank money market. The deposit rate $R_{t}^{D}$ is assumed to equal the policy rate $R_{t}^{M}$ due to arbitrage conditions (Freixas and Rochet, 1997, p. 57) and is therefore exogenous for the individual bank. Given the balance sheet constraint:

$$
L_{j, t}=D_{j, t}+B_{j, t}
$$

which implies that the loan volume equals the level of deposits - that is chosen by households - and a cash injection taken up in the form of central bank credits at the prevailing policy rate, the profit function (21) can be rewritten as:

$$
\Pi_{j, t+i}^{b a n k}=\left(R_{j, t}^{L}-R_{t+i}^{M}\right) L_{j, t+i} .
$$

The maximization of the intertemporal profit function, which is subject to the firms' loan demand function (18), yields the following first-order condition:

$$
E_{t} \sum_{i=0}^{\infty} \tau^{i} \Delta_{i, t+i}\left[(1-\zeta)+\zeta \frac{R_{t+i}^{M}}{R_{j, t}^{L *}}\right]\left(\frac{R_{j, t}^{L *}}{R_{t+i}^{L}}\right)^{-\zeta} L_{t+i}=0,
$$

where $R_{j, t}^{L *}$ is the optimal reset price of bank $j$.

\footnotetext{
${ }^{5}$ This assumption is consistent with the identifying restrictions of the VAR model considered below, according to which the loan rate reacts contemporaneously to a monetary policy shock.
} 


\subsection{The Linearized Model}

For the empirical analysis we use a log-linearized version of the model, where the equations are linearized around their steady states. We employ the following conventions: assume that $X_{t}$ is a strictly positive variable and $\bar{X}$ denotes the steady state, then the variable $\hat{X}_{t}$ is the logarithmic deviation of the variable from its steady state, $\hat{X}_{t}=\ln \left(X_{t}\right)-\ln (\bar{X})$.

The consumption Euler-equation with habit formation is given by:

$$
\hat{Y}_{t}=\frac{1}{1+h} E_{t-1} \hat{Y}_{t+1}+\frac{h}{1+h} \hat{Y}_{t-1}-\frac{1-h}{(1+h) \sigma} E_{t-1}\left(\hat{R}_{t}^{M}-\pi_{t+1}-\hat{\xi}_{t}+\hat{\xi}_{t+1}\right),
$$

where the $\log$-linearized income identity $\hat{Y}_{t}=\hat{C}_{t}$ is applied to substitute out consumption by income. $\hat{Y}_{t}$ denotes the output gap; the inflation rate $\pi_{t}$ is defined as $\pi_{t}=\hat{P}_{t}-\hat{P}_{t-1}$. In the absence of habit formation, i.e. $h=0$, equation (25) collapses to a purely forward-looking IS-equation.

The inflation adjustment equation is given by a hybrid New Keynesian Phillips curve that accounts for the cost channel and monopolistic competition in the loan market:

$$
\pi_{t}=\gamma_{f} E_{t-1} \pi_{t+1}+\gamma_{b} \pi_{t-1}+\kappa E_{t-1}\left(\hat{R}_{t}^{L}+\hat{S}_{t}\right)
$$

where

$$
\begin{aligned}
\gamma_{f} & =\frac{\beta \theta}{\theta+\omega[1-\theta(1-\beta)]} \\
\gamma_{b} & =\frac{\omega}{\theta+\omega[1-\theta(1-\beta)]} \\
\kappa & =\frac{(1-\theta)(1-\beta \theta)(1-\omega)}{\theta+\omega[1-\theta(1-\beta)]} \frac{\alpha \zeta}{\alpha \zeta(1-\epsilon)+\epsilon(\zeta-1)}
\end{aligned}
$$

The dynamics of the inflation rate depends on the size of $\gamma_{b}$ in relation to $\gamma_{f}$, where it holds that $\gamma_{f}+\gamma_{b}=1$. The parameter $\kappa$ is the sensitivity of inflation with respect to the gross loan rate $\hat{R}_{t}^{L}$ and the real unit labor costs $\hat{S}_{t}$. The innovation compared to a standard New Keynesian Phillips curve is the introduction of the gross loan rate, which implies the existence of a cost channel as deviations of the nominal gross loan rate from its steady state are a source of cyclical movements in the inflation process. Moreover, the slope of the Phillips curve $\kappa$ increases with the degree of monopolistic competition in the banking sector which is measured 
by $1 / \zeta$. For values of $\zeta$ approaching infinity (i.e. perfect competition) the second fraction of $\kappa$ converges to $\alpha /[1+(1-\alpha)(\epsilon-1)]$.

The behavior of the banking industry is governed by the following equation (see Appendix B for details):

$$
\hat{R}_{t}^{L}=\frac{\beta \tau}{1+\beta \tau^{2}} E_{t} \hat{R}_{t+1}^{L}+\frac{\tau}{1+\beta \tau^{2}} \hat{R}_{t-1}^{L}+\frac{(1-\beta \tau)(1-\tau)}{1+\beta \tau^{2}} \hat{R}_{t}^{M},
$$

which can be rewritten as:

$$
\Delta \hat{R}_{t}^{L}=\beta E_{t} \Delta \hat{R}_{t+1}^{L}-\frac{(1-\beta \tau)(1-\tau)}{\tau}\left(\hat{R}_{t}^{L}-\hat{R}_{t}^{M}\right),
$$

where $\Delta \hat{R}_{t}^{L}=\hat{R}_{t}^{L}-\hat{R}_{t-1}^{L}$. Equation (29) implies that a change in the average loan rate is triggered by a wedge between the current money market rate and the current loan rate. If the fraction of banks $\tau$ that stick with the last period's loan rate goes to zero, the pass-through will be complete and $\hat{R}_{t}^{L}=\hat{R}_{t}^{M}$ at all times t. This corresponds to the approach taken by Ravenna and Walsh (2006) who focus on banks operating under perfect competition. If instead $\tau$ is a positive fraction, loan rates will respond stickily and the pass-through is incomplete in the short-run.

Real unit labor costs evolve according to:

$$
\hat{S}_{t}=\left(\frac{1-\alpha+\eta}{\alpha}+\frac{\sigma}{1-h}\right) \hat{Y}_{t}-\frac{h \sigma}{1-h} \hat{Y}_{t-1}-\frac{1+\eta}{\alpha} \hat{A}_{t}-\hat{\xi}_{t}
$$

where we used the definition of real unit labor cost $\hat{S}_{t}=\hat{w}_{t}+\hat{N}_{t}-\hat{Y}_{t}$ and the log-linearized production technology $\hat{Y}_{t}=\hat{A}_{t}+\alpha \hat{N}_{t}$.

The model is closed by the central bank's reaction function. The central bank sets the short-term interest rate according to a forward-looking Taylor-type policy rule:

$$
\hat{R}_{t}^{M}=\delta \hat{R}_{t-1}^{M}+(1-\delta)\left[\phi_{\pi} E_{t} \pi_{t+2}+\phi_{\hat{Y}} \hat{Y}_{t}\right]+z_{t}^{M},
$$

where $\delta$ captures the degree of interest rate smoothing, $\phi_{\pi}$ and $\phi_{\hat{Y}}$ are the central bank's reaction coefficients with respect to the expected inflation rate and the output gap and $z_{t}^{M}$ denotes the monetary policy shock. The reason for choosing $t+2$ as horizon for inflation expectations is purely empirical as it delivers the best fit when the model is estimated for the Euro area. In the following, we concentrate 
on a monetary policy shock only and ignore taste shocks $\hat{\xi}_{t}$ and technology shocks $\hat{A}_{t}$. The main reason for this is that we are interested in investigating the behavior of banks in propagating monetary policy disturbances.

\section{Empirical Results}

Following Rotemberg and Woodford (1998) and Christiano, Eichenbaum, and Evans (2005) we estimate the model for the Euro area - the log-linearized equations (25) to (31) - by using a minimum distance approach that consists of two steps. First, we estimate a VAR to generate empirical impulse responses to a monetary policy shock. Second, we estimate the model parameters by matching the theoretical impulse responses as closely as possible with the empirical impulse responses.

\subsection{Empirical Impulse Responses}

We employ a VAR model for the Euro area of the form:

$$
Z_{t}=A(L) Z_{t-1}+\mu+\varepsilon_{t}
$$

where $Z_{t}$ is a vector of endogenous variables, $\mu$ is a vector of constant terms and $\varepsilon_{t}$ is a vector of error terms that are assumed to be white noise. The vector $Z_{t}$ comprises the variables:

$$
Z_{t}=\left(\mathrm{GDP}_{t}, \mathrm{INFL}_{t}, \mathrm{RM}_{t}, \mathrm{RL}_{t}\right)^{\prime},
$$

where $\mathrm{GDP}_{t}$ stands for real output, $\mathrm{INFL}_{t}$ for the inflation rate, $\mathrm{RM}_{t}$ for the policy rate of the central bank, which is approximated by a short-term money market rate, and $\mathrm{RL}_{t}$ for the loan rate. ${ }^{6}$

The VAR model is estimated in levels. The sample period starts in 1990Q1 and ends in 2002Q4. The output level is expressed in logs, while the inflation rate and the interest rates are in percent. The vector of constant terms comprises a linear trend and a constant. Choosing a lag length of two ensures that the error terms dismiss signs of autocorrelation and conditional heteroscedasticity. ${ }^{7}$

\footnotetext{
${ }^{6}$ See Appendix C for a description of the data used.

${ }^{7}$ We ran a variety of tests for misspecification and stability, which are not reported here, but which are available upon request.
} 
Based on the VAR model, we generate impulse responses of the variables in $Z_{t}$ to a monetary policy shock, which is identified by imposing a triangular orthogonalization. The ordering of the variables implies that an innovation in the policy rate affects the output level and the inflation rate with a lag of one quarter, while the loan rate is affected within the same quarter. Figure 1 displays the impulse responses of the variables to a one standard deviation monetary policy shock. The simulation horizon covers 20 quarters. The dotted lines are $95 \%$ Hall percentile confidence intervals (Hall, 1992) that are derived from a bootstrap procedure with 2000 replications. The solid lines denote impulse responses, which are calculated as the median of the bootstrapped impulse responses. Except for real GDP, all variables are expressed in units of percentage points at an annual rate. Real GDP is expressed percent terms.

As in Peersman and Smets (2003) and Smets and Wouters (2002) our findings show that the output level declines by degrees following a monetary policy shock, reaching a trough after four quarters, and returns to the baseline value subsequently. The reaction of the output level corresponds with the evolution of the output gap. The inflation rate falls slowly and shows a significant decline only after five quarters. Following the trough, which is reached after around eight quarters, it gradually reverts to baseline. The money market rate increases immediately, then declines temporally, and returns to the baseline value subsequently. The loan rate follows a similar pattern as the money market rate, but the reaction is less pronounced. The sluggish reaction of the loan rate to a monetary policy shock indicates the incomplete pass-through.

\subsection{Methodology}

The estimation of our model builds on the following matrix representation:

$$
\Gamma_{0} X_{t}=\Gamma_{1} X_{t-1}+\Omega_{z} z_{t}+\Omega_{\vartheta} \vartheta_{t}
$$

where $X_{t}$ is the state vector, $z_{t}$ is a vector of shocks and $\vartheta_{t}$ is a vector of expectational errors that satisfy $E_{t} \vartheta_{t+1}=0$ for all $t$. The matrices $\Gamma_{0}, \Gamma_{1}, \Omega_{z}$ and $\Omega_{\vartheta}$ contain the structural parameters of the model (Sims, 2001).

The closed loop dynamics of the model, which serves as a starting point to 
Figure 1: Empirical Impulse Responses
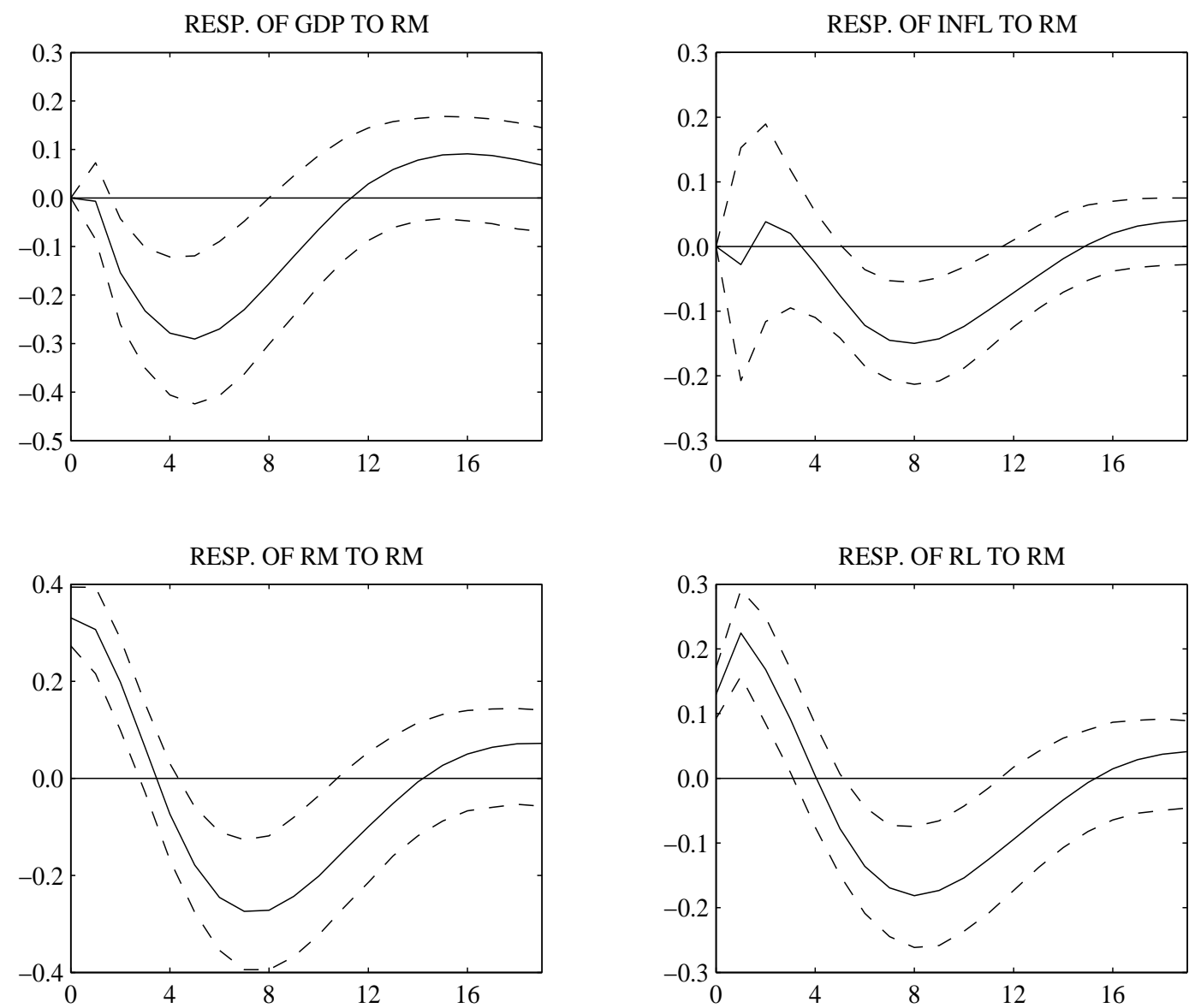

Notes: Orthogonalized impulse responses to a monetary policy shock. The dotted lines are $95 \%$ Hall percentile confidence intervals computed from a bootstrap procedure with 2000 replications. The solid lines denote impulse responses, which are calculated as the median of the bootstrapped impulse responses. The horizontal axis is in quarters. 
generate impulse responses, is given by:

$$
X_{t}(\varrho)=\Theta_{X}(\varrho) X_{t-1}+\Theta_{z}(\varrho) z_{t}
$$

where the rational expectations equilibrium is solved by using the method developed by Sims (2001). ${ }^{8}$ For the matching of the impulse responses, we estimate the following set of parameters:

$$
\varrho=\left(h \theta \omega \tau \delta \phi_{\pi} \phi_{\hat{Y}}\right),
$$

by minimizing a distance measure between the theoretical impulse responses and the empirical impulse responses.

The remaining parameters were calibrated according to estimates typically found in the literature (see Table 1). The discount factor $\beta$ is fixed to 0.99, implying an annual steady state interest rate of 4 per cent. The degree of risk aversion $\sigma$ (which is the inverse of the intertemporal elasticity of substitution) is assumed to equal one, which corresponds to the assumption of a log utility function (see for example Del Negro et al., 2005, for a similar assumption). The values for the share of labor in production $\alpha$ and the elasticity of labor supply $\eta$ are set in accordance with the mean values of the prior distribution in Del Negro et al. (2005). The steady-state mark-up of intermediate good producers over nominal marginal costs is set at 20 per cent, implying $\epsilon=6$. This value for $\epsilon$ is somewhat higher than in Del Negro et al. (2005) $(\epsilon=4.33)$, but lower than for example in Leith and Malley $(2005)(\epsilon=11)$. The steady-state mark-up of the banking industry is set at 40 per cent $(\zeta=3.5)$ and has been calculated as the average percentage deviation of the nominal loan rate $\mathrm{RL}_{t}$ from the nominal money market rate $\mathrm{RM}_{t}$ over the sample period.

The need for calibrating a sub-set of parameters is typically encountered in the literature when DSGE models are estimated. One reason for this is that in an unconstrained estimate these parameters often take values that are implausible. The decision of which parameters to calibrate, however, is rarely discussed and varies from paper to paper. We therefore propose to distinguish calibrated from estimated parameters by their role for the dynamics of the economy. While

\footnotetext{
${ }^{8}$ We used the MATLAB files gensys.m, gensysct.m, qzdiv.m, qzdivct.m, and qzswitch.m, which can be downloaded from Chris Sims's web page.
} 
Table 1: Calibrated Parameters

\begin{tabular}{lcc}
\hline \hline Parameter & Symbol & Calibration \\
\hline Discount factor & $\beta$ & 0.99 \\
Risk aversion & $\sigma$ & 1.00 \\
Labor supply elasticity & $\eta$ & 2.00 \\
Production function & $\alpha$ & 0.75 \\
Monopoly power of firms & $1 / \epsilon$ & $1 / 6$ \\
Monopoly power of banks & $1 / \zeta$ & $1 / 3.5$ \\
\hline \hline
\end{tabular}

the calibrated parameters fully determine the evolution of the flexible price equilibrium of the economy (which takes into account the monopoly power of firms in the intermediate goods market and of the banking industry), the estimated parameters reflect the inefficiencies resulting from real rigidities $(h)$ and nominal frictions $(\theta, \omega, \tau)$ and the related policy response $\left(\delta, \phi_{\pi}, \phi_{\hat{Y}}\right)$.

The estimator of $\varrho$ minimizes the following distance function (Christiano, Eichenbaum, and Evans, 2005):

$$
J=(\hat{\Psi}-\Psi(\varrho))^{\prime} V^{-1}(\hat{\Psi}-\Psi(\varrho)),
$$

where $\hat{\Psi}$ denote the empirical impulse responses, $\Psi(\varrho)$ describe the mapping from $\varrho$ to the theoretical impulse responses and $V$ is the weighting matrix with the sample variances of $\hat{\Psi}$ on the diagonal. The weighting matrix assures that those point estimates with a smaller standard deviation are given a higher priority. ${ }^{9}$

\subsection{Minimum Distance Estimation}

We estimate our model by matching impulse responses to a monetary policy shock. The impulse responses are plotted in Figure 2 together with the $95 \%$ error

\footnotetext{
${ }^{9}$ We used the MATLAB optimization routine fminunc, which attempts to find a minimum of a scalar function of several variables, starting at an initial estimate. This is generally referred to as unconstrained nonlinear optimization. The algorithm uses the BFGS Quasi-Newton method with a mixed quadratic and cubic line search procedure. A limitation of the algorithm is that it might only give local solutions. Therefore, we checked whether our estimates are robust against

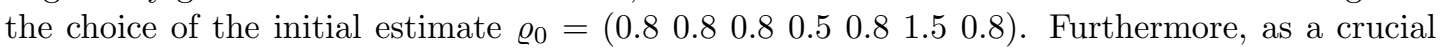
prerequisite for the reliability of the estimates we took care that the optimization algorithm converges.
} 
bands. The theoretical impulse responses conform quite closely with the empirical impulse responses and lie in general within the confidence intervals. The model replicates reasonably well the humped-shaped response of output, the progressive drop in inflation and the response of the interest rates. Solely slight differences emerge in the timing of the troughs of output and inflation, which are reached earlier.

Figure 2: Model Impulse Responses
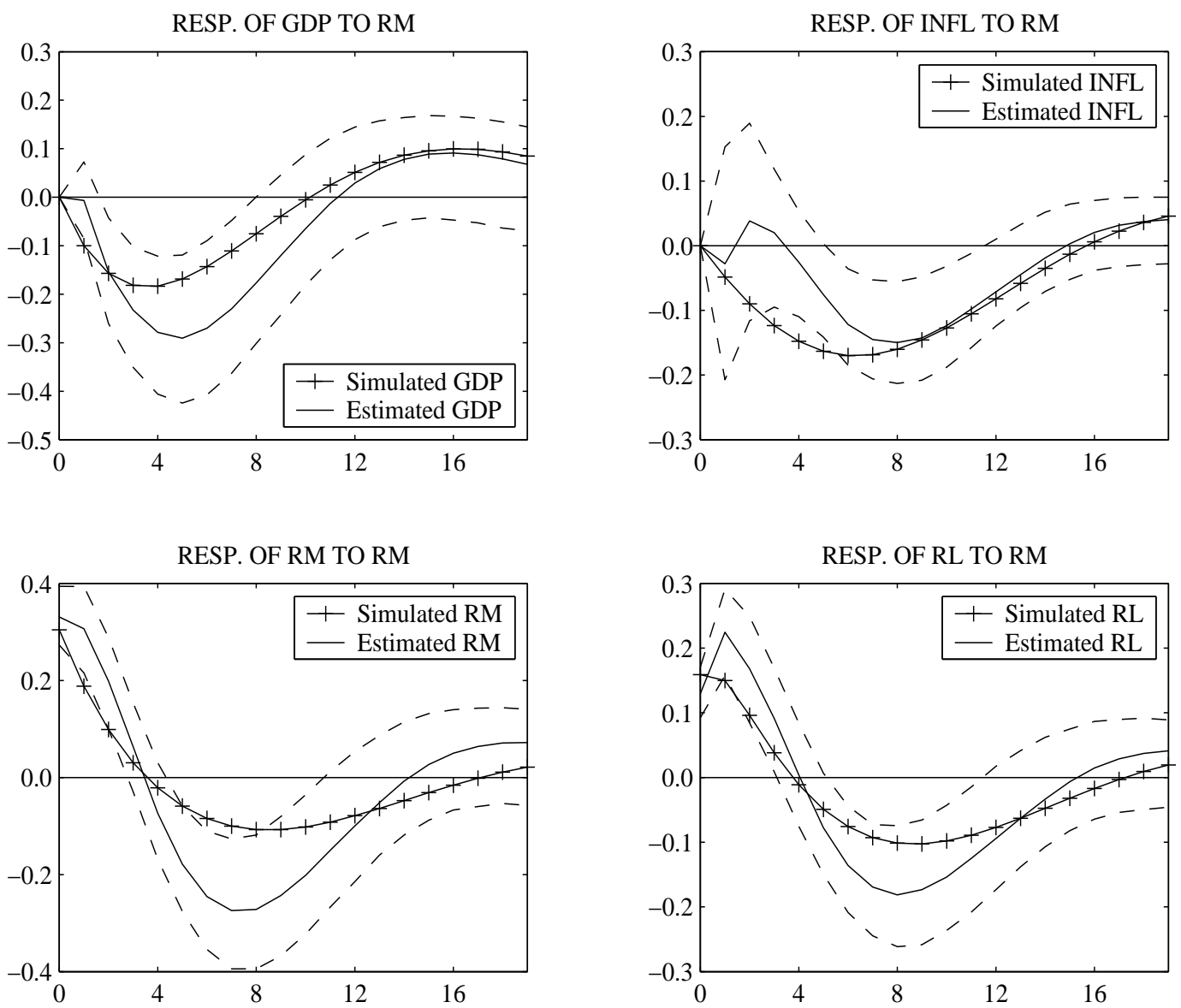

Notes: For the estimated impulse responses see notes to Figure 1.

Table 2 summarizes the point estimates of the parameters in the vector $\varrho$ that minimize the distance function. ${ }^{10}$ The standard errors for $\varrho$ are computed using

\footnotetext{
${ }^{10}$ For a check of the robustness of the estimates against changes in the calibrated parameters see Appendix D.
} 
Table 2: Parameter Estimates

\begin{tabular}{lccc}
\hline \hline Parameter & Symbol & Estimate & Standard error \\
\hline Habit formation & $h$ & 0.89 & 0.02 \\
Price stickiness & $\theta$ & 0.67 & 0.15 \\
Rule-of-thumb pricing & $\omega$ & 0.90 & 0.04 \\
Loan rate stickiness & $\tau$ & 0.36 & 0.05 \\
\hline Taylor rule: smoothing & $\delta$ & 0.73 & 0.06 \\
Taylor rule: inflation & $\phi_{\pi}$ & 1.07 & 0.20 \\
Taylor rule: output gap & $\phi_{\hat{Y}}$ & -0.13 & 0.14 \\
\hline \hline
\end{tabular}

the delta function method. ${ }^{11}$ Concerning the Taylor rule, we find that interest rate smoothing is important, that the output gap turns out to be insignificant and that the central bank reacts positively to the expected inflation rate in $t+2$.

In the consumption Euler-equation the estimated degree of habit formation is substantial and indicates that the hump shaped response in the output gap to a monetary policy shock seems to be mainly driven by habits itself. This estimate appears to validate the claim of Rudebusch and Fuhrer (2005) that the degree of forward-lookingness in consumption is limited. This finding is in line with other studies that do not account for the capital formation process explicitly (Giannoni and Woodford, 2004, Nelson, Andrés and López-Salido, 2005).

\footnotetext{
${ }^{11}$ This footnote is taken from Altig et al. (2005). Let $g(\hat{\varrho}, \hat{\Psi})=J_{\hat{\varrho}}(\hat{\varrho}, \hat{\Psi})=0$ denote the first order condition associated with the solution to the minimization of (35). Denote the mapping in (35) by $\hat{\varrho}=f(\hat{\Psi})$. To obtain the sampling variance of the estimator, $\hat{\varrho}$, as a function of the sampling variance of $\hat{\Psi}$, the delta function method approximates $f(\hat{\Psi})$ by its linear expansion about the true value of $\Psi, \Psi^{0}$. That is, $f(\hat{\Psi}) \approx f\left(\Psi^{0}\right)+f^{\prime}\left(\Psi^{0}\right)\left(\hat{\Psi}-\Psi^{0}\right)$. Here, $f\left(\Psi^{0}\right)=\varrho^{0}$, where $\varrho^{0}$ is the true value of $\varrho$, by the consistency of our estimator. Then, $\sqrt{N}\left(\hat{\varrho}_{N}-\varrho^{0}\right)$ is asymptotically Normally distributed with mean zero and variance $f^{\prime}\left(\Psi^{0}\right) W f^{\prime}\left(\Psi^{0}\right)^{T}$, where $N$ is the number of bootstraps used in the calculation of the empirical impulse responses, $T$ indicates the transposition operator, and $W$ is the asymptotic variance-covariance matrix of $\sqrt{N}\left(\hat{\Psi}_{N}-\Psi^{0}\right)$. We use the implicit function theorem to approximate $f^{\prime}\left(\Psi^{0}\right)$ by $-g_{1}^{-1} g_{2}$, where $g_{1}$ and $g_{2}$ are the partial derivatives of $g$ with respect to $\varrho$ and $\Psi$, evaluated at $\varrho^{0}$ and $\Psi^{0}$. In practice, $W$ is replaced by its sample estimate, as are $\varrho^{0}$ and $\Psi^{0}$ in the expression for $f^{\prime}$. The standard errors reported in Table 2 are the relevant diagonal terms in $f^{\prime}\left(\Psi^{0}\right) W f^{\prime}\left(\Psi^{0}\right)^{T}$, after taking square roots and dividing by $\sqrt{N}$. Note that the weighting matrix $V$ in (35) is a diagonal matrix composed of the diagonal elements of $W$. For the calculation of the standard errors we used modified versions of the MATLAB files ComputeStdErrors.m, g1g2Func.m, and MomentFunction.m, which can be downloaded from Lawrence Christiano's web page.
} 
The estimated degree of Calvo pricing implies that prices are fixed on average for three quarters. This is in line with the estimates for $\theta$ that can be found in Del Negro et al. (2005) $(\theta=0.67)$ and Rabanal $(2003)(\theta=0.64)$. The estimate for rule-of-thumb price setting $\omega$ is somewhat higher compared to other studies, which might reflect the fact that we do not explicitly allow for indexation in the wage formation process.

The significant estimate for $\tau$ reveals that the banking industry plays a meaningful role in propagating monetary shocks. The degree of loan rate stickiness $\tau$ was estimated to be 0.36 , which implies that loan rates are fixed on average for 1.5 quarters. This result can be considered as a contribution to the literature as we extend earlier findings by Ravenna and Walsh (2006) who only model the banking industry as a neutral conveyor of monetary shocks. Their model of the banking industry can be regarded as a special case of our model with $\tau=0$.

\section{Relevance of the Structure of the Banking System for the Cost Channel}

The estimates reported in the last section reveal that the macroeconomic relevance of the cost channel for the Euro area is determined by the institutional structure of the financial system. On the one hand, the degree to which changes in the money market rate are passed through to the loan rate depends on the Calvo parameter $\tau$, which measures the fraction of banks in each period that keep their loan rates unchanged. Moreover, since banks are forward-looking and their decisions are affected by their expectations about future monetary policy, the interest rate pass-through also depends on the policy rule parameters. On the other hand, the impact of the loan rate on inflation is determined by the slope of the Phillips curve, which depends - among other structural parameters - on the importance of banker-customer relationships and hence on the degree of competition in the banking industry $\zeta$. In the following we will discuss the relevance of these parameters for the transmission of monetary impulses to inflation via the cost channel. 


\subsection{Pass-Through from the Money Market Rate to the Loan Rate}

For the analysis of the impact of $\tau$ and the policy rule parameters on the interest rate pass-through we simplify our model by excluding any feedback from inflation and output on the central bank's reaction function (i.e. $\phi_{\pi}=\phi_{\hat{Y}}=0$ in equation $(31))$ :

$$
\hat{R}_{t}^{M}=\delta \hat{R}_{t-1}^{M}+z_{t}^{M}
$$

Thus, the modified reaction function (36) and equation (28) form a system of expectational difference equations for $\hat{R}_{t}^{M}$ and $\hat{R}_{t}^{L}$ with $z_{t}^{M}$ as an exogenous monetary policy shock, for which the minimum-state-variable (MSV) rational expectations solution (McCallum, 1983) for $\hat{R}_{t}^{L}$ can be computed analytically (see Appendix E for a derivation):

$$
\hat{R}_{t}^{L}=\tau \hat{R}_{t-1}^{L}+\frac{(1-\beta \tau)(1-\tau)}{(1-\beta \tau \delta)} \hat{R}_{t}^{M}
$$

A Calvo-type staggered price setting approach on the part of the banking industry nests the following implications for the interest rate pass-through:

Proposition 4.1 The immediate pass-through of a monetary policy shock $z_{t}^{M}$ to the loan rate $\hat{R}_{t}^{L}$ becomes more incomplete when the fraction of banks $\tau$ that stick to last period's loan rates rises.

Proof The immediate pass-through refers to the pass-through in the period in which the monetary policy shock $z_{t}^{M}$ hits the banking industry. Thus, as time $t-1$ variables are at their zero-steady-state, $\hat{R}_{t}^{M}=z_{t}^{M}$ and $\hat{R}_{t}^{L}=f(\beta, \delta, \tau) \hat{R}_{t}^{M}$ where the immediate pass-through coefficient is given by $f(\beta, \delta, \tau)=\frac{(1-\beta \tau)(1-\tau)}{(1-\beta \tau \delta)}$. The first derivative of the immediate pass-through coefficient $f$ with respect to $\tau$ is given by $f_{\tau}(\beta, \delta, \tau)=\frac{-\beta \delta \tau^{2}+2 \beta \tau+(\beta \delta-\beta-1)}{(1-\beta \tau \delta)^{2}}$. The sign of $f_{\tau}(\beta, \delta, \tau)$ is determined by the nominator, which is for $\beta, \delta \in] 0 ; 1]$ a downward-opening parabola with two positive roots, $\tau_{1 / 2}=\frac{1 \pm \sqrt{(1-\delta)(1-\beta \delta)}}{\beta \delta}$. It can be shown by straightforward algebra that the smaller of the two roots is strictly larger than one, if $\delta<1 / \beta$, which is always true. As a consequence, $f_{\tau}(\beta, \delta, \tau)$ is strictly negative for $\tau \in[0 ; 1]$ and $\beta, \delta \in] 0 ; 1]$. 
Thus, according to Proposition 4.1, the immediate interest rate pass-through is mainly determined by $\tau$. In particular, for a bank-based system we conjecture that the immediate interest rate pass-through is incomplete, which is confirmed by our point estimate of $\tau=0.36$. In the case of a market-based system $\tau$ should be significantly smaller and close to zero. Note that for the limiting case of $\tau=0$, the model collapses towards a regime of complete interest rate passthrough (Ravenna and Walsh, 2006), where the money market rate $\hat{R}_{t}^{M}$ equals the loan rate $\hat{R}_{t}^{M}$ at each point in time $t$.

For the central bank's impact on the immediate pass-through the following proposition holds:

Proposition 4.2 The immediate pass-through of a monetary policy shock $z_{t}^{M}$ to the loan rate $\hat{R}_{t}^{L}$ becomes less incomplete when the central bank's smoothing parameter $\delta$ rises.

Proof The first derivative of the immediate pass-through coefficient $f$ with respect to $\delta, f_{\delta}(\beta, \delta, \tau)=\frac{(1-\beta \tau)(1-\tau) \beta \tau}{(1-\beta \tau \delta)^{2}}$, is greater than or equal to zero for $\beta, \delta, \tau \in[0 ; 1]$.

Thus, according to Proposition 4.2, an interest rate smoothing central bank reduces the initial incompleteness of the pass-through and works against the loan rate stickiness of the banking industry. Note, however, that $\hat{R}_{t}^{L}$ will always be smaller than $\hat{R}_{t}^{M}$ in the period in which the monetary policy shock $z_{t}^{M}$ hits the banking industry (i.e. the immediate pass-through will always be incomplete), as $0 \leq f(\beta, \delta, \tau)<1$ for all $\beta, \delta \in[0 ; 1]$ and $\tau \in] 0 ; 1] .{ }^{12}$ Thus, the main determinant of the immediate pass-through is the degree of loan rate stickiness $\tau$.

For the periods following the shock the stickiness of the loan rate is also an important determinant of the pass-through:

Proposition 4.3 The adjustment process of $\hat{R}_{t}^{L}$ to $\hat{R}_{t}^{M}$ becomes more persistent when the fraction of banks $\tau$ that stick to last period's loan rates rises.

Proof The role of $\tau$ for the adjustment process is harder to grasp using analytical methods. For this reason we resort to a graphical proof. Figure 3 shows that for a value of $\delta$ equal to 0.73 the incompleteness of the pass-through, $\hat{R}_{t}^{L}-\hat{R}_{t}^{M}$, becomes

\footnotetext{
${ }^{12}$ The immediate pass-through is complete only for $\tau=0$.
} 
more persistent following a monetary policy shock when the degree of loan rate stickiness $\tau$ increases. As a byproduct Figure 3 also illustrates Proposition 4.1. Note that the dynamic laws of motion of $\hat{R}_{t}^{M}$ and $\hat{R}_{t}^{L}$ are given by equations (36) and (37).

Figure 3: Proof of Proposition 4.3

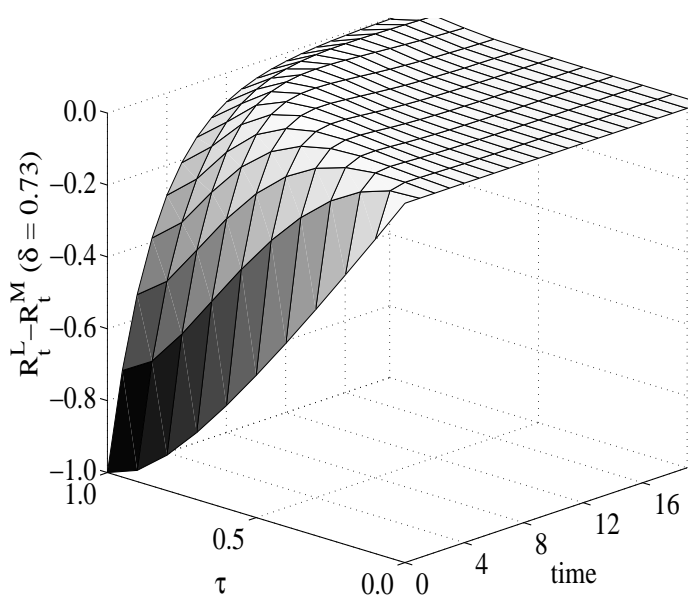

Thus, according to Proposition 4.3, a banking system that sets loan rates in a Calvo-type manner dampens the impact of changes in the money market rate not only in the period, in which the monetary policy shock hits the economy, but also in the subsequent periods. A bank-based financial system therefore acts as a shelter for bank-dependent firms from variable monetary policy rates. This is the basic feature of the implicit interest rate insurance models of Fried and Howitt (1980) and Berger and Udell (1992), which deliver an economic rationale for why bank-customer relationships persist.

Note, however, that the central bank also has an interest for smoothing interest rates, which not only influences the evolution of $\hat{R}_{t}^{M}$, but also that of $\hat{R}_{t}^{L}$ :

Proposition 4.4 The adjustment process of $\hat{R}_{t}^{L}$ to $\hat{R}_{t}^{M}$ becomes more persistent when the degree of interest rate smoothing $\delta$ rises.

Proof Again we resort to a graphical proof. Figure 4 shows that for $\tau=0.36$ the incompleteness of the pass-through, $\hat{R}_{t}^{L}-\hat{R}_{t}^{M}$, becomes more persistent following 
a monetary policy shock when the degree of interest rate smoothing on the part of the central bank $\delta$ increases. As a byproduct Figure 4 also illustrates Proposition 4.2 .

Figure 4: Proof of Proposition 4.4

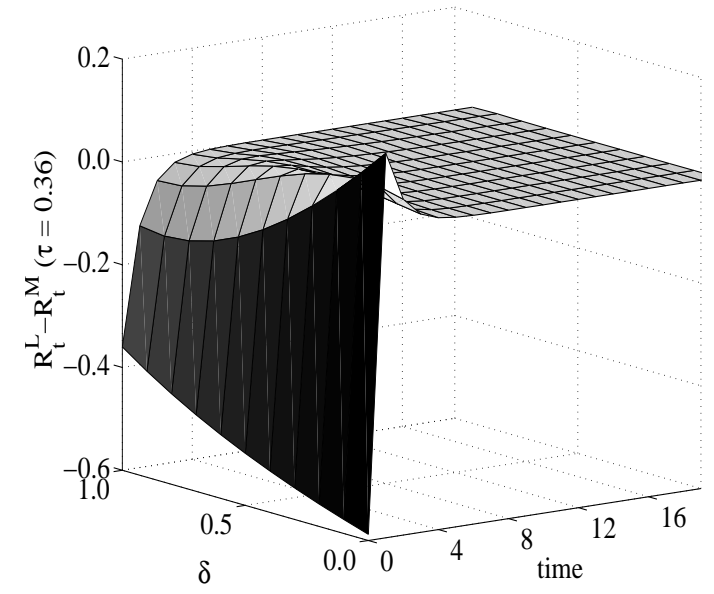

Thus, Proposition 4.4 states that banks smooth interest rates over and above the central bank's tendency to adjust interest rates only gradually in response to changes in economic conditions. The pass-through is therefore conditioned on the conduct of monetary policy as the banking industry expects further interest rate steps by monetary authorities in the same direction. By contrast, if the central bank's preference for smoothing money market rates is low, the banking industry keeps loan rates above the money market rate in the periods following the positive shock, which implies a more than complete pass-through.

\subsection{Impact of the Loan Rate on Inflation}

Apart from the pass-through of the money market rate to the loan rate the macroeconomic relevance of the cost channel depends on the slope coefficient of the Phillips curve $\kappa$, which represents the elasticity of inflation with respect to real marginal costs. Concerning the impact of the competitive structure of the financial system on $\kappa$ the following proposition can be formulated: 
Proposition 4.5 A higher degree of competition in the banking industry $\zeta$ decreases the slope coefficient $\kappa$ of the Phillips curve. The macroeconomic importance of the cost channel, however, remains unchanged as the aggregate demand channel, which counteracts the cost channel through its impact on real unit labor costs, is affected in equal measure.

Proof The second fraction in equation (27), which we denote by $g(\alpha, \epsilon, \zeta)=$ $\frac{\alpha \zeta}{\alpha \zeta(1-\epsilon)+\epsilon(\zeta-1)}$, is a decreasing function of $\zeta .^{13}$

Thus, if the prevalence of relationship banking diminishes and if, as a consequence, the banking industry becomes more competitive (i.e. $\zeta \rightarrow \infty$ ), the impact of real marginal costs on inflation declines. In Figure 5 the response of real marginal costs $\hat{\varphi}_{t}$ to a monetary policy shock for the model estimated in Section 3 is decomposed into into its two constituents, the loan rate $\hat{R}_{t}^{L}$ and real unit labor $\operatorname{costs} \hat{S}_{t}$. On the one hand, it shows that the traditional aggregate demand channel induces consumers to reallocate consumption into the future following a restrictive monetary policy shock, which reduces current demand for goods. As production decisions are demand determined, firms induce production cuts by reducing labor input, which in turn curtails real marginal costs. On the other hand, the banking industry passes through the increase in the money market rate to the loan rate. In sum, the initial decrease in real unit labor costs is partially compensated by the increase in the loan rate. However, as the degree of competition in the banking industry $\zeta$ neither influences the dynamics of $\hat{R}_{t}^{L}$ nor that of $\hat{S}_{t}$, the relative importance of the cost channel remains unaffected by changes in $\kappa$.

\subsection{Cost Channel versus Aggregate Demand Channel}

Figure 5 also illustrates that for the Euro area the demand channel effect dominates the cost channel effect by a large margin. Thus, on the basis of our estimates presented in Section 3 we conclude that the cost channel is not strong enough to be of quantitative importance. This finding is in line with Rabanal (2003) who estimated a small-scale macroeconomic model for the United States and the Euro

\footnotetext{
${ }^{13}$ Note that $g(\alpha, \epsilon, \zeta)$ is discontinuous. Even though $g_{\zeta}(\alpha, \epsilon, \zeta)=-\frac{\alpha \epsilon}{(\alpha \zeta(1-\epsilon)+\epsilon(\zeta-1))^{2}}<0$ for all $\zeta \in]-\infty ; \infty\left[\right.$ and $\alpha, \epsilon>0, \zeta$ has to be larger than $\frac{\epsilon}{\alpha+\epsilon-\alpha \epsilon}>0$ so as to ensure that $g(\alpha, \epsilon, \zeta)$, and hence $\kappa$, is positive.
} 
Figure 5: Decomposition of Real Marginal Costs

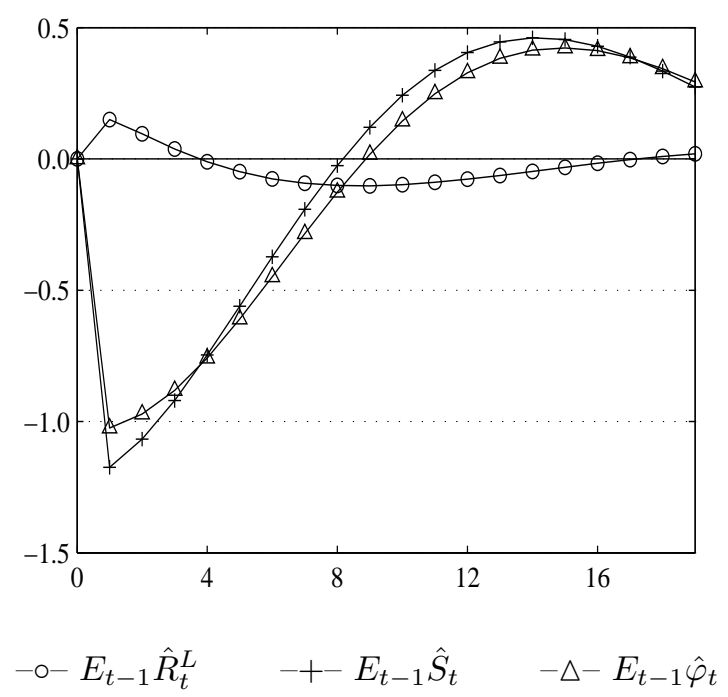

area that accounts for the cost channel. In his model banks operate under perfect competition. Contrary to other papers, he divides firms into a fraction that must pay workers before they sell their product and a remaining fraction of firms that pays the wage bill at the end of the period. Although he finds evidence of the cost channel in both countries, he concludes that the estimated fraction of cost channel firms is quantitatively unimportant.

There are three factors that would contribute to an increase in the relative importance of the cost channel. The first is related to the the degree of loan rate stickiness, and hence to the institutional structure of the banking system. If $\tau$ decreases, the pass-through becomes more complete as the banking system's role as a damper of monetary impulses vanishes. In the extreme case of $\tau=0$, the loan rate exactly follows the money market rate and the cost channel effect is maximal, whereas the evolution of real unit labor costs remains unaffected. A quantification of the increase in the relative importance of the cost channel after the modification of a single parameter is shown in Figure 6. For the first four quarters following the monetary policy shock the bars depict by how much the loan rate counteracts the impact of real unit labor costs on real marginal costs. Specifically, for $t=1,2,3,4$ each bar is calculated as $\left(\hat{\varphi}_{t} / \hat{S}_{t}-1\right) \cdot 100 \%$. In the case of $\tau=0$, the largest impact can be recorded for $t=1$, in which the loan rate 
increases marginal costs by $16 \%$ instead of $13 \%$ in the case of $\tau=0.36$.

Figure 6: Increasing the Relative Importance of the Cost Channel

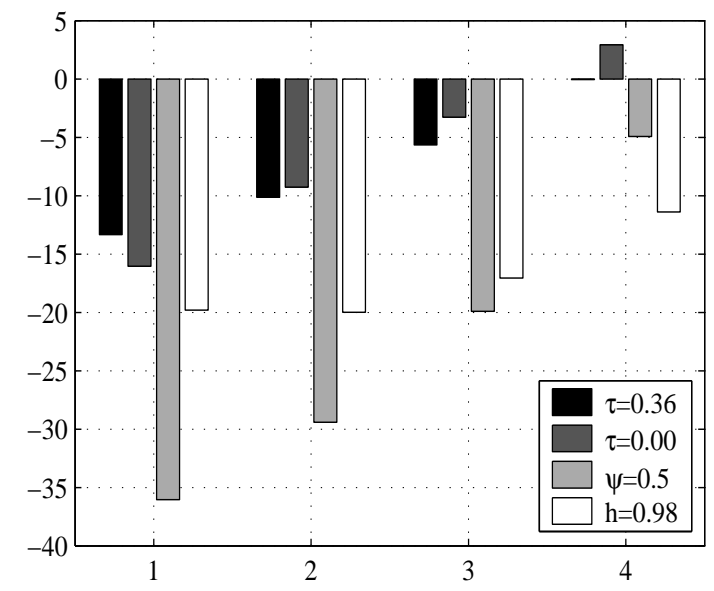

A second way to increase the relative importance of the cost channel is to allow for a more than complete initial pass-through. This line has been taken by Chowdhury, Hoffmann, and Schabert (2006) who - instead of providing an explicit microfoundation - postulate the following static relationship between the money market rate and the loan rate: $\hat{R}_{t}^{L}=(1+\psi) \hat{R}_{t}^{M}$. A positive $\psi$ is motivated by "financial market imperfections", which basically represent the costs that are related to the likelihood of defaults on loans. ${ }^{14}$ Figure 6 shows that in the case of $\psi=0.5$ the amplification of the monetary impulse reduces marginal costs significantly stronger than in the complete-pass-through case.

A more persistent effect can also be attained by an increase in the habit formation parameter $h$. As this diminishes the impact of monetary policy on real unit labor costs $S_{t}$, the demand channel is weakened without having any impact on the cost channel. Figure 6 shows that in the case of $h=0.98$ the reduction of real marginal costs by the loan rate only phases out gradually and still amounts to $-11 \%$ in period four following the monetary policy shock.

\footnotetext{
${ }^{14}$ Note that in our simple model we abstain from modeling capital accumulation. Hence, by rationalizing a more than complete pass-through by the existence of risky investments, we would clearly abandon our general equilibrium framework.
} 


\section{Conclusion}

The cost channel assigns banks an important role in the transmission of monetary policy by stating that firms require credit to finance production. Firms base their pricing decision on credit conditions because their marginal production costs are directly affected by interest rates. As a consequence, the drop in prices following a monetary contraction is mitigated as credit conditions deteriorate with higher interest rates.

We presented a New Keynesian model that dwells on the role of banks in the cost channel of monetary policy. Banks were assumed to extent credit to firms in an environment of monopolistic competition by setting the loan rate according to a Calvo-type staggered price setting approach. Only a fraction of banks reset their loan rate after a change in the policy rate, while the remaining fraction kept their loan rate unchanged, which implied that the adjustment of the aggregate loan rate to a monetary policy shock is sluggish.

We estimated a VAR model for the Euro area, which showed that output declines by degrees after a monetary policy shock, inflation reacts inertial and the loan rate follows the policy rate, but the reaction is less pronounced. The latter confirms the findings of de Bondt (2005), according to which the pass-through from money market rates to loan rates is incomplete.

For an assessment of the relevance of the cost channel in the Euro area, we estimated our general equilibrium model by adopting a minimum distance approach, which matches the theoretical impulse responses to the empirical impulse responses to a monetary policy shock. The results showed that, (i) frictions on the loan market play a meaningful part for the propagation of monetary policy shocks, as the adjustment of loan rates to changes in money market rates is sticky, and (ii) the cost channel is operating, but the effect is weak since inflation is mainly driven by changes in unit labor costs rather than interest rates.

Our main conclusion was that the strength of the cost channel in the Euro area is mitigated as banks shelter firms from monetary policy shocks by smoothing lending rates. Although firms base their pricing decision on credit conditions, the impact on inflation dynamics arising through changes in interest rates emerges as quantitatively unimportant. This is consistent with Christiano, Eichenbaum, 
and Evans (2005) and Rabanal (2003), who conclude that the overall effect of the cost channel is only minor. 


\section{Appendices}

\section{A Derivation of the Firms' Real Marginal Costs}

When the production of intermediate good producers is subject to diminishing returns to scale $(\alpha<1)$ and when firms maintain long-term business relationships with specific banks, firms with different production levels face different marginal costs. Relating the firm specific real marginal costs

$$
\varphi_{j, t+i}=\frac{1}{\alpha} R_{j, t+i}^{L} S_{j, t+i}
$$

to average real marginal costs

$$
\varphi_{t+i}=\frac{1}{\alpha} R_{t+i}^{L} S_{t+i}
$$

yields

$$
\varphi_{j, t+i}=\varphi_{t+i}\left(\frac{R_{j, t+i}^{L}}{R_{t+i}^{L}}\right)\left(\frac{S_{j, t+i}}{S_{t+i}}\right) .
$$

The first term in parentheses can be replaced by $\left(L_{j, t+i} / L_{t+i}\right)^{1 / \zeta}$ when making use of equation (18). Recall that loans $L_{j, t+i}$ are taken up for paying the wage bill $W_{t+i} N_{j, t+i}$. Thus, $L_{j, t+i} / L_{t+i}$ can be replaced by $N_{j, t+i} / N_{t+i}$. Using the definition of real unit labor costs $S_{j, t+i}$ given by equation (16), the second term in parentheses can be rewritten as $\left(N_{j, t+i} / N_{t+i}\right)\left(Y_{t+i} / Y_{j, t+i}\right)$. After substituting out labor using the production function (9), equation (A.2) becomes

$$
\varphi_{j, t+i}=\varphi_{t+i}\left(\frac{Y_{j, t+i}}{Y_{t+i}}\right)^{\frac{\zeta(1-\alpha)-1}{\alpha \zeta}} .
$$

Equation (7) can finally be used to replace the term in parentheses, so that we end up with equation (17) of the main text.

\section{B Loan Rate Evolution}

Banks face frictions as in Calvo (1983), which implies a staggered price setting. The loan rate $R_{t}^{L}$ evolves each period as a weighted average of a fraction of banks $1-\tau$ that are allowed to reoptimize the loan rate and a fraction $\tau$ that stick with 
the last period loan rate $R_{t-1}^{L}$. The Dixit-Stiglitz price index in period $t$ then satisfies:

$$
\begin{aligned}
R_{t}^{L} & =\left[\int_{0}^{1}\left(R_{j, t}^{L}\right)^{1-\zeta} d j+\int_{0}^{1}\left(R_{j, t-1}^{L}\right)^{1-\zeta} d j\right]^{\frac{1}{1-\zeta}} \\
& =\left[(1-\tau)\left(R_{j, t}^{L *}\right)^{1-\zeta}+\tau\left(R_{j, t-1}^{L}\right)^{1-\zeta}\right]^{\frac{1}{1-\zeta}}
\end{aligned}
$$

where $R_{j, t}^{L *}$ denotes the reoptimized loan rate. Forward-looking bank $j$ sets its loan rate to satisfy the first-order condition (24), which can be restated according to:

$$
R_{j, t}^{L}=\frac{\zeta}{\zeta-1} \frac{E_{t}\left[\sum_{i=0}^{\infty} \tau^{i} \Delta_{i, t+i}\left(R_{t+i}^{L}\right)^{\zeta} L_{t+i} R_{t+i}^{M}\right]}{E_{t}\left[\sum_{i=0}^{\infty} \tau^{i} \Delta_{i, t+i}\left(R_{t+i}^{L}\right)^{\zeta} L_{t+i}\right]} .
$$

Log-linearizing this expression and recognizing that all banks face the same marginal costs gives:

$$
\begin{aligned}
\hat{R}_{t}^{L *} & \left.=(1-\tau \beta) E_{t}\left[\sum_{i=0}^{\infty}(\tau \beta)^{i} \hat{R}_{t+1}^{M}\right)\right] \\
& =(1-\tau \beta) \hat{R}_{t}^{M}+\beta \tau E_{t} \hat{R}_{t+1}^{L *} .
\end{aligned}
$$

Log-linearizing expression (B.1) and rearranging terms yields:

$$
\hat{R}_{t}^{L *}=\frac{1}{(1-\tau)} \hat{R}_{t}^{L}-\frac{\tau}{(1-\tau)} \hat{R}_{t-1}^{L}
$$

and

$$
\hat{R}_{t+1}^{L *}=\frac{1}{(1-\tau)} \hat{R}_{t+1}^{L}-\frac{\tau}{(1-\tau)} \hat{R}_{t}^{L}
$$

Making use of these relationships and rearranging terms finally gives equation (28):

$$
\hat{R}_{t}^{L}=\frac{\tau \beta}{1+\beta \tau^{2}} E_{t} \hat{R}_{t+1}^{L}+\frac{\tau}{1+\beta \tau^{2}} \hat{R}_{t-1}^{L}+\frac{(1-\beta \tau)(1-\tau)}{1+\beta \tau^{2}} \hat{R}_{t}^{M}
$$

\section{Data Base}

The data is taken from the Euro Area Wide Model (AWM) - see Fagan, Henry, and Mestre (2001) and www.ecb.org - except for the loan rate data, which has been kindly provided by the ECB. The sample covers the period from 1990Q1 to 2002Q4 due to the availability of the loan rate data. 
1. GDP: Log of real GDP, seasonally adjusted (AWM code: YER).

2. INFL: Inflation rate, annualized change of GDP deflator in percent, seasonally adjusted (AWM code: YED).

3. RM: Short-term nominal interest rate, in percent (AWM code: STN).

4. RL: Retail bank lending rates to enterprizes; average of rates up to one year and over one year, nominal in percent.

\section{Robustness of the Estimates}

When a subset of model parameters is calibrated, an important matter is whether the estimates of the remaining model parameters are robust against changes in the calibrated parameters. In the literature there is above all uncertainty about the values for $\sigma, \epsilon, \alpha$ and $\eta$, whereas $\beta$ is always set to values close to $0.99 .^{15}$ Instead of assuming log-utility (as in Del Negro et al., 2005) Leith and Malley (2005), for instance, estimate the degree of risk aversion $\sigma$ and report values for the Euro area close to 2. Concerning the steady-state mark-up in the intermediate goods market a number of papers (e.g. Leith and Malley, 2005, and Welz, 2006) assume a value of 10 per cent $(\epsilon=11)$. There are, however, several authors that assume a significantly higher mark-up. Amato and Laubach (2003), for instance, set it to 15 per cent $(\epsilon=7.9)$, and Del Negro et al. (2005) even set it to 23 per cent $(\epsilon=4.3)$. The elasticity of marginal disutility of labor $\eta$ and the share of labor in production $\alpha$ were also calibrated by Leith and Malley (2005) who set them to 1.5 and 0.68 , respectively. Del Negro et al. (2005), by contrast, included these two parameters in their vector of estimates and obtained values of 2.3 and 0.85 , respectively.

The most important result is that the degree of loan rate stickiness $\tau$ is very robust against the chosen values of those parameters that determine the evolution of the flexible-price equilibrium of the economy. Irrespective of the calibration of $\sigma, \epsilon, \alpha$ and $\eta$, the estimate of $\tau$ lies in the close neighborhood of our baseline estimate of 0.36 (see Figures 7 to 10 ).

\footnotetext{
${ }^{15}$ The steady-state mark-up of the banking industry $1 /(\zeta-1)$ was calculated using observable data (see Section 3.2) and is therefore not subject to uncertainty.
} 
Figure 7: Robustness of the Estimates against Variations of $\sigma$
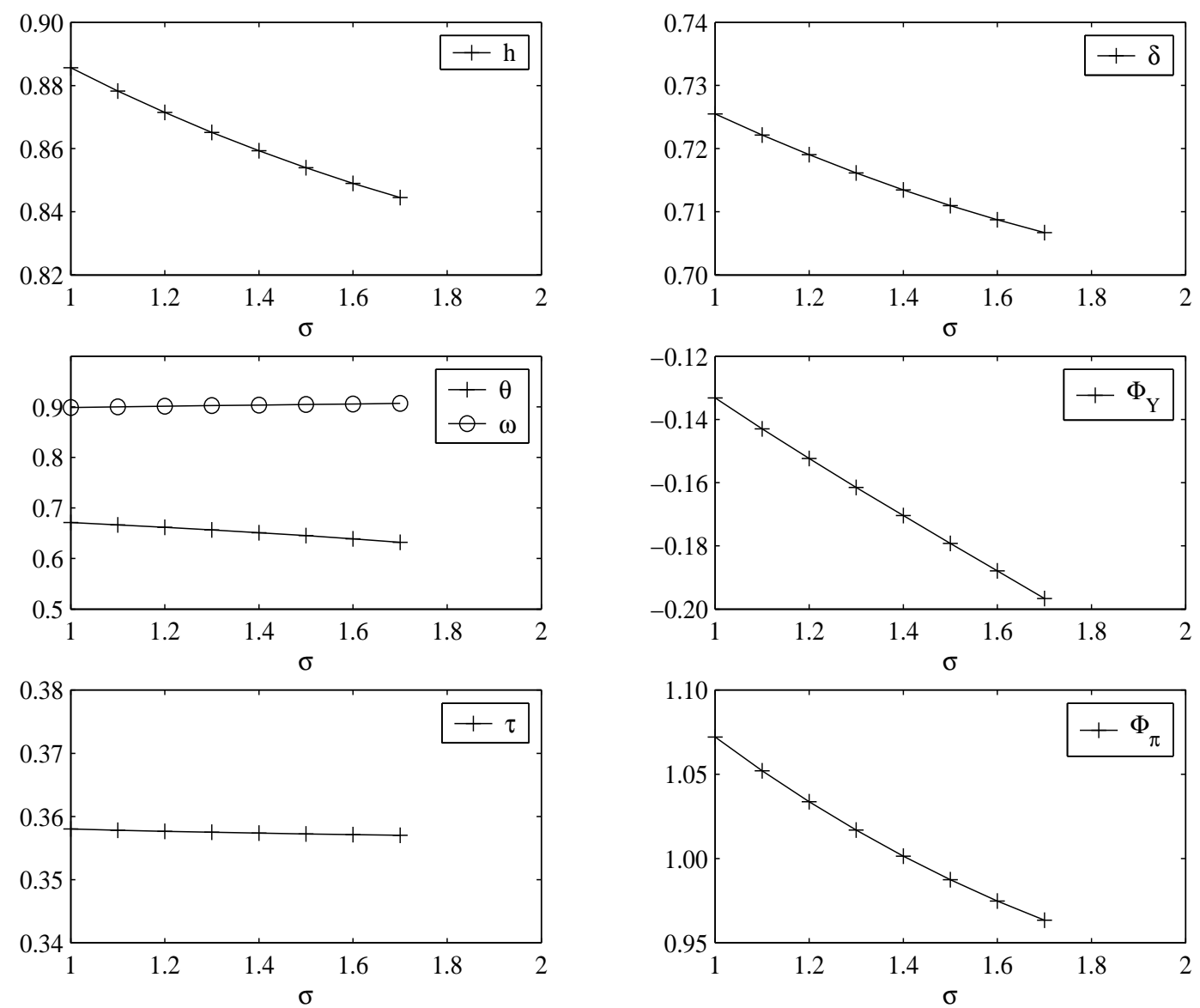

Notes: Missing values occur when the optimization routine does not converge. 
Figure 8: Robustness of the Estimates against Variations of $\epsilon$
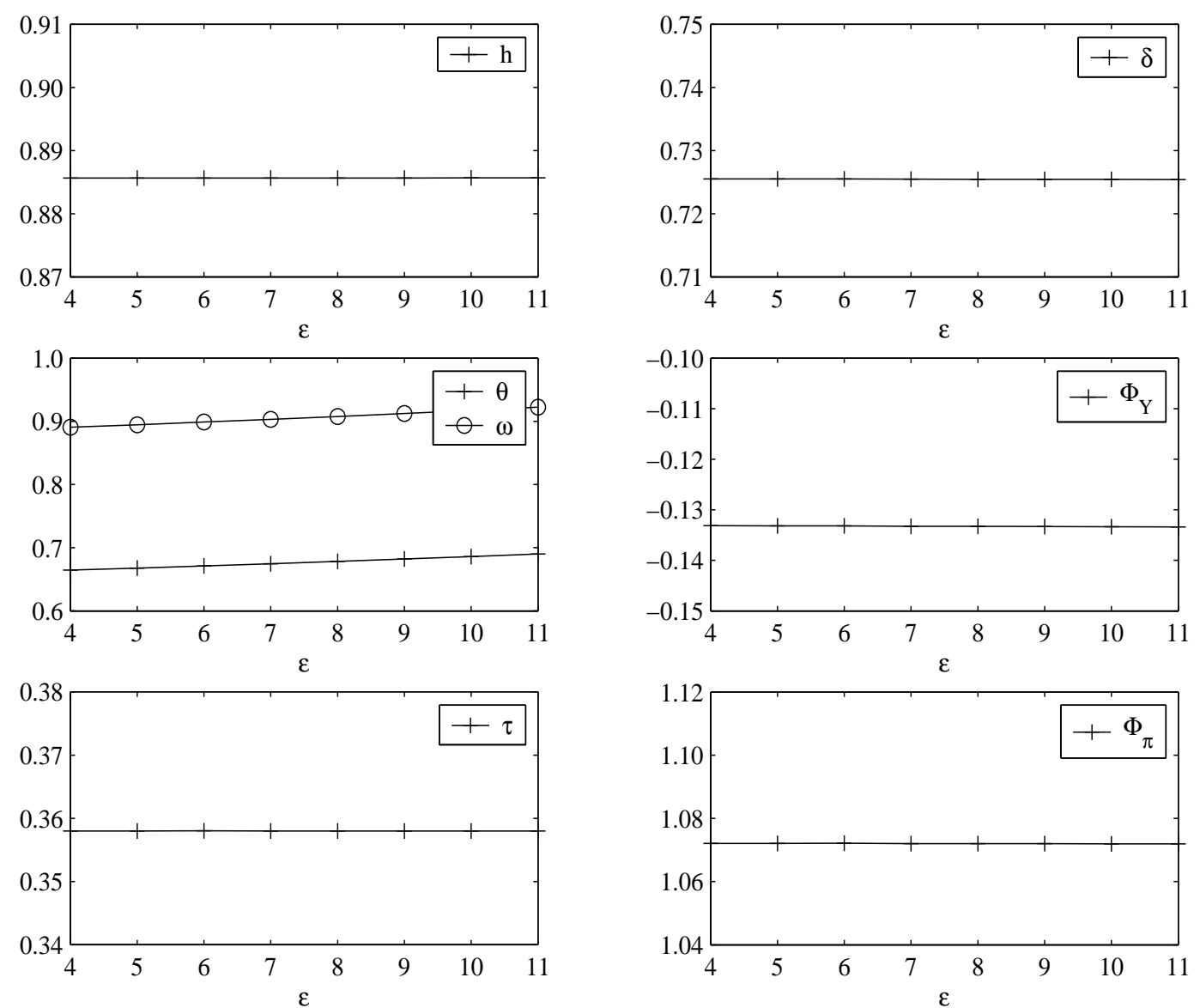
Figure 9: Robustness of the Estimates against Variations of $\alpha$
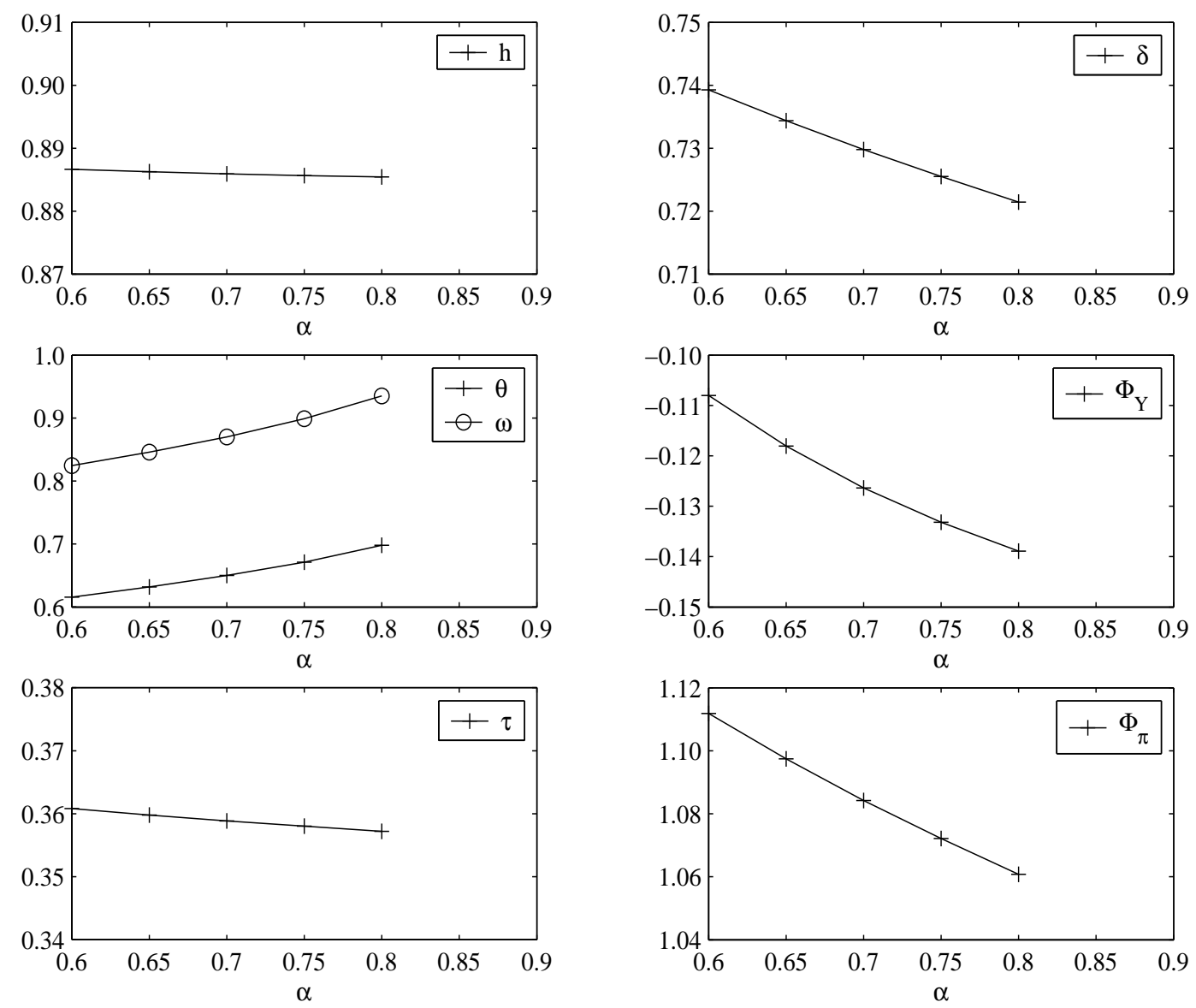

Notes: Missing values occur when the optimization routine does not converge. 
Figure 10: Robustness of the Estimates against Variations of $\eta$
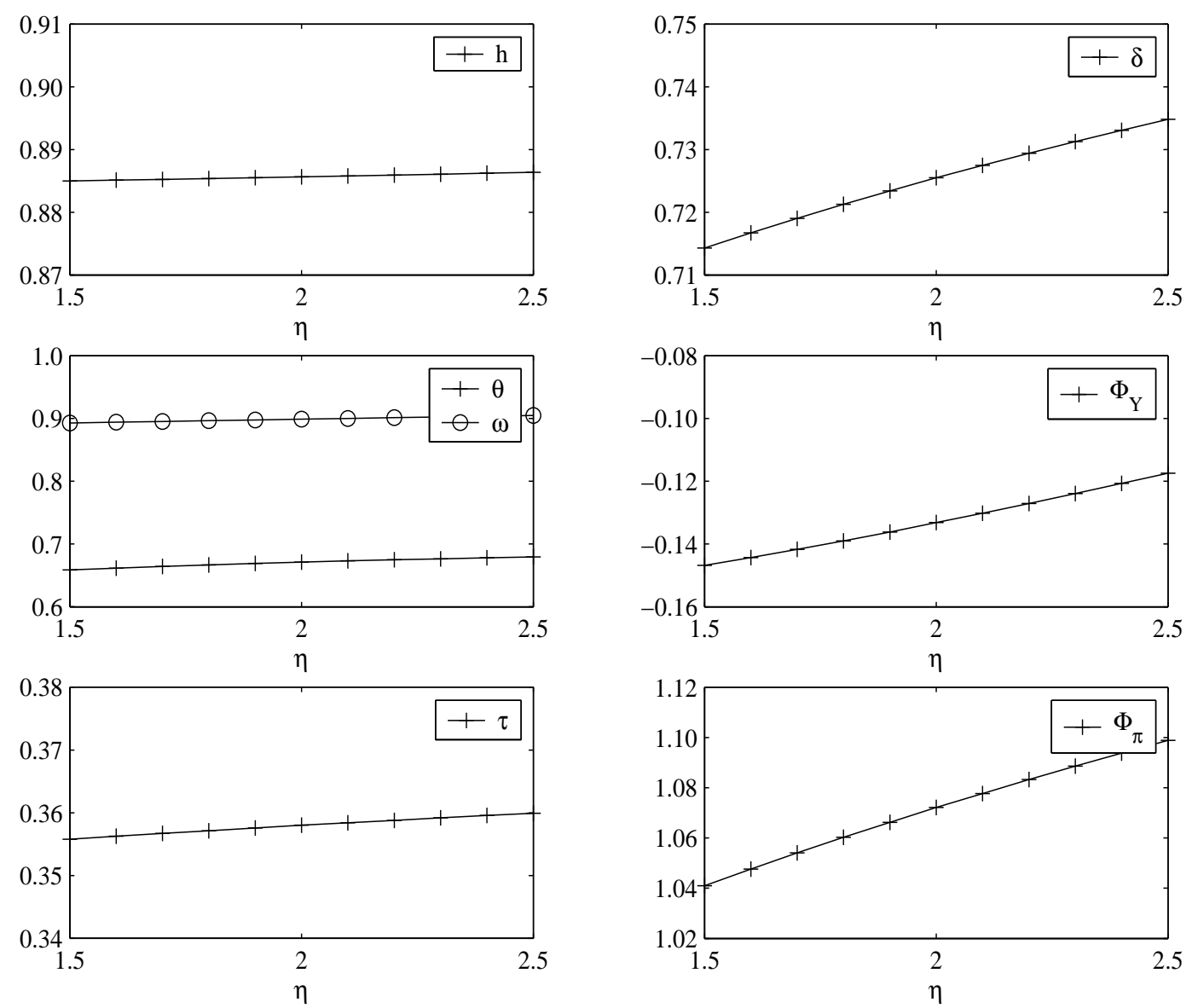
As for the remaining parameter estimates, the following results can be stated. The inverse of the intertemporal elasticity of consumption $\sigma$ mainly influences the estimate of the habit formation parameter $h$ and the policy rule parameters $\delta, \phi_{\hat{Y}}$ and $\phi_{\pi}$, which all decrease with a higher value of $\sigma$ (see Figure 7). Changes in $\epsilon$ only have an impact on the price setting behavior of intermediate good producers. With a higher steady-state mark-up (a lower $\epsilon$ ), both the degree of price stickiness $\theta$ and the fraction of rule-of-thumb price setters $\omega$ increases (see Figure 8). The production function parameter $\alpha$ mainly influences the price setting behavior and the reaction of the central bank. A higher share of labor in production (i.e. a higher value of $\alpha$ ) increases the degree of price stickiness $\theta$ and the fraction of rule-of-thumb price setters $\omega$ and deceases the response of the central bank to deviations of expected inflation and output from their steady state values (see Figure 9). Changes in $\eta$ only have an impact on the estimates of the policy rule parameters $\delta, \phi_{\hat{Y}}$ and $\phi_{\pi}$, which all turn out to be increasing in $\eta$ (see Figure 10).

\section{E Derivation of the MSV Solution}

After excluding any feedback from inflation and output on the central bank's reaction function (i.e. $\phi_{\pi}=\phi_{\hat{Y}}=0$ in equation (31)), our model can be reduced to the following system of expectational difference equations for $\hat{R}_{t}^{M}$ and $\hat{R}_{t}^{L}$ with $z_{t}^{M}$ as exogenous monetary policy shock:

$$
\begin{gathered}
\hat{R}_{t}^{L}=\frac{\beta \tau}{1+\beta \tau^{2}} E_{t} \hat{R}_{t+1}^{L}+\frac{\tau}{1+\beta \tau^{2}} \hat{R}_{t-1}^{L}+\frac{(1-\beta \tau)(1-\tau)}{1+\beta \tau^{2}} \hat{R}_{t}^{M}, \\
\hat{R}_{t}^{M}=\delta \hat{R}_{t-1}^{M}+z_{t}^{M} .
\end{gathered}
$$

Let us posit a fundamental (minimum state variable) solution of the following generic form (McCallum,1983):

$$
\hat{R}_{t}^{L}=\phi_{1} \hat{R}_{t-1}^{L}+\phi_{2} \hat{R}_{t-1}^{M}
$$

where the coefficients $\phi_{1}$ and $\phi_{2}$ remain to be determined. Eliminating the endogenous variable $E_{t} \hat{R}_{t+1}^{L}$ in (E.1) by $E_{t} \hat{R}_{t+1}^{L}=E_{t} \phi_{1} \hat{R}_{t}^{L}+E_{t} \phi_{2} \hat{R}_{t+1}^{M}$, and equating coefficients by comparing the resulting expression with (E.1) leads to the following conditions for the undetermined coefficients:

$$
\frac{\beta \tau}{1+\beta \tau^{2}} \phi_{1}^{2}-\phi_{1}+\frac{\tau}{1+\beta \tau^{2}}=0
$$




$$
\left.\phi_{2}\left(1-\frac{\beta \tau}{1+\beta \tau^{2}}\right)\left(\phi_{1}+\delta\right)\right)-\frac{(1-\beta \tau)(1-\tau)}{1+\beta \tau^{2}}=0 .
$$

Computing the stable root of $\phi_{1}$ in (E.4) yields: $\phi_{1}=\tau$. Inserting $\phi_{1}=\tau$ into (E.5) gives a solution for $\phi_{2}$, with $\phi_{2}=\frac{(1-\beta \tau)(1-\tau)}{1+\beta \tau \delta}$. Making use of these results in (E.3), the MSV solution can be stated as:

$$
\hat{R}_{t}^{L}=\tau \hat{R}_{t-1}^{L}+\frac{(1-\beta \tau)(1-\tau)}{(1-\beta \tau \delta)} \hat{R}_{t}^{M}
$$

which is equivalent to equation (37). 


\section{References}

Altig, D., L. J. Christiano, M. Eichenbaum, And J. Linde (2005): "FirmSpecific Capital, Nominal Rigidities and the Business Cycle," NBER Working Paper 11034, National Bureau of Economic Research.

Amato, J., and T. Laubach (2003): "Rule-of-thumb Behaviour and Monetary Policy," European Economic Review, 47, 791-831.

Barth, M. J., and V. A. Ramey (2000): "The Cost Channel of Monetary Transmission," NBER Working Paper 7675, National Bureau of Economic Research.

Berger, A. N., and G. F. Udell (1992): "Some Evidence on the Empirical Significance of Credit Rationing," Journal of Political Economy, 100, 10471077.

Calvo, G. A. (1983): "Staggered Prices in a Utility-Maximizing Framework," Journal of Monetary Economics, 12, 383-398.

Chowdhury, I., M. Hoffmann, and A. Schabert (2006): "Inflation Dynamics and the Cost Channel of Monetary Transmission," European Economic Review, 50, 995-1016.

Christiano, L. J., M. Eichenbaum, and C. Evans (1997): "Sticky Price and Limited Participation Models of Money: A Comparison," European Economic Review, 41, 1201-1249.

(2005): "Nominal Rigidities and the Dynamic Effects of a Shock to Monetary Policy," Journal of Political Economy, 113, 1-45.

Cottarelli, C., And A. Kourelis (1994): "Financial Structure, Bank Lending Rates, and the Transmission Mechanism of Monetary Policy," IMF Staff Reports, 41, 587-623.

DE Bondt, G. J. (2005): "Interest Rate Pass-Through: Empirical Results for the Euro Area," German Economic Review, 6, 37-78. 
Del Negro, M., F. Schorfheide, F. Smets, and R. Wouters (2005): "On the Fit and Forecasting Performance of New Keynesian Models," CEPR Discussion Paper 4848, Centre for Economic Policy Research.

Ehrmann, M., L. Gambacorta, J. Martínez-Pagés, P. Sevestre, and A. Worms (2001): "Financial Systems and the Role of Banks in Monetary Policy Transmission in the Euro Area," ECB Working Paper 105, European Central Bank.

Fagan, G., J. Henry, and R. Mestre (2001): "An Area-Wide Model (AWM) for the Euro Area," ECB Working Paper 42, European Central Bank.

Freixas, X., And J.-C. Rochet (1997): Microeconomics of Banking. MIT Press Cambridge, Massachusetts, Massachusetts.

Fried, J., ANd P. Howitt (1980): "Credit Rationing and Implicit Contract Theory," Journal of Money, Credit, and Banking, 12, 471-487.

Gali, J., M. Gertler, and J. D. Lopez-Salido (2001): "European Inflation Dynamics," European Economic Review, 45, 1237-1270.

Giannoni, M. P., and M. Woodford (2004): "Optimal Inflation-Targeting Rules," in The Inflation Targeting Debate, ed. by B. S. Bernanke, and M. Woodford, pp. 93-162, Chicago. University of Chicago Press.

Hall, P. (1992): The Bootstrap and Edgeworth Expansion. Springer, New York.

Leith, C., And J. Malley (2005): "Estimated General Equilibrium Models for the Evaluation of Monetary Policy in the US and Europe," European Economic Review, 49, 2137-2159.

McCallum, B. T. (1983): "On Non-Uniqueness in Rational Expectations Models: An Attempt at Perspective," Journal of Monetary Economics, 11, 139-168.

Nelson, E., J. Andrés, and D. LóPez-Salido (2005): "Sticky-Price Models and the Natural Rate Hypothesis," Journal of Monetary Economics, 52, 10251053. 
Peersman, G., and F. Smets (2003): "The Monetary Transmission Mechanism in the Euro Area: Evidence from VAR Analysis," in Monetary Policy Transmission in the Euro Area, ed. by I. Angeloni, A. Kashyap, and B. Mojon, pp. 36-55. Cambridge University Press.

Rabanal, P. (2003): "The Cost Channel of Monetary Policy: Further Evidence for the United States and the Euro Area," IMF Working Paper 149, International Monetary Fund.

Ravenna, F., And C. E. Walsh (2006): "Optimal Monetary Policy with the Cost Channel," Journal of Monetary Economics, 53, 199-216.

Rotemberg, J. J., And M. Woodford (1991): "Markups and the Business Cycle," in NBER Macroeconomics Annual, ed. by O. J. Blanchard, and S. Fischer, pp. 63-129, Cambridge, Mass. MIT Press.

(1998): "An Optimization-Based Econometric Framework for the Evaluation of Monetary Policy: Expanded Version," NBER Technical Working Paper 233, National Bureau of Economic Research.

Rudebusch, G., And M. Fuhrer (2005): "Estimating the Euler Equation for Output," Journal of Monetary Economics, 51, 1133-1353.

Sims, C. A. (2001): "Solving Linear Rational Expectations Models," Computational Economics, 20, 1-20.

Smets, F., And R. Wouters (2002): "An Estimated Stochastic Dynamic General Equilibrium Model of the Euro Area," Journal of the European Economic Association, 1, 1123-1175.

Welz, P. (2006): “Assessing Predetermined Expectations in the Standard Sticky Price Model: A Bayesian Approach," ECB Working Paper 621, European Central Bank. 


\section{CESifo Working Paper Series}

(for full list see www.cesifo-group.de)

1752 Helge Berger and Michael Neugart, Labor Courts, Nomination Bias, and Unemployment in Germany, June 2006

1753 Chris van Klaveren, Bernard van Praag and Henriette Maassen van den Brink, A Collective Household Model of Time Allocation - a Comparison of Native Dutch and Immigrant Households in the Netherlands, June 2006

1754 Marko Koethenbuerger, Ex-Post Redistribution in a Federation: Implications for Corrective Policy, July 2006

1755 Axel Dreher, Jan-Egbert Sturm and Heinrich Ursprung, The Impact of Globalization on the Composition of Government Expenditures: Evidence from Panel Data, July 2006

1756 Richard Schmidtke, Private Provision of a Complementary Public Good, July 2006

1757 J. Atsu Amegashie, Intentions and Social Interactions, July 2006

1758 Alessandro Balestrino, Tax Avoidance, Endogenous Social Norms, and the Comparison Income Effect, July 2006

1759 Øystein Thøgersen, Intergenerational Risk Sharing by Means of Pay-as-you-go Programs - an Investigation of Alternative Mechanisms, July 2006

1760 Pascalis Raimondos-Møller and Alan D. Woodland, Steepest Ascent Tariff Reforms, July 2006

1761 Ronald MacDonald and Cezary Wojcik, Catching-up, Inflation Differentials and Credit Booms in a Heterogeneous Monetary Union: Some Implications for EMU and new EU Member States, July 2006

1762 Robert Dur, Status-Seeking in Criminal Subcultures and the Double Dividend of ZeroTolerance, July 2006

1763 Christa Hainz, Business Groups in Emerging Markets - Financial Control and Sequential Investment, July 2006

1764 Didier Laussel and Raymond Riezman, Fixed Transport Costs and International Trade, July 2006

1765 Rafael Lalive, How do Extended Benefits Affect Unemployment Duration? A Regression Discontinuity Approach, July 2006

1766 Eric Hillebrand, Gunther Schnabl and Yasemin Ulu, Japanese Foreign Exchange Intervention and the Yen/Dollar Exchange Rate: A Simultaneous Equations Approach Using Realized Volatility, July 2006 
1767 Carsten Hefeker, EMU Enlargement, Policy Uncertainty and Economic Reforms, July 2006

1768 Giovanni Facchini and Anna Maria Mayda, Individual Attitudes towards Immigrants: Welfare-State Determinants across Countries, July 2006

1769 Maarten Bosker and Harry Garretsen, Geography Rules Too! Economic Development and the Geography of Institutions, July 2006

1770 M. Hashem Pesaran and Allan Timmermann, Testing Dependence among Serially Correlated Multi-category Variables, July 2006

1771 Juergen von Hagen and Haiping Zhang, Financial Liberalization in a Small Open Economy, August 2006

1772 Alessandro Cigno, Is there a Social Security Tax Wedge?, August 2006

1773 Peter Egger, Simon Loretz, Michael Pfaffermayr and Hannes Winner, Corporate Taxation and Multinational Activity, August 2006

1774 Jeremy S.S. Edwards, Wolfgang Eggert and Alfons J. Weichenrieder, The Measurement of Firm Ownership and its Effect on Managerial Pay, August 2006

1775 Scott Alan Carson and Thomas N. Maloney, Living Standards in Black and White: Evidence from the Heights of Ohio Prison Inmates, 1829 - 1913, August 2006

1776 Richard Schmidtke, Two-Sided Markets with Pecuniary and Participation Externalities, August 2006

1777 Ben J. Heijdra and Jenny E. Ligthart, The Transitional Dynamics of Fiscal Policy in Small Open Economies, August 2006

1778 Jay Pil Choi, How Reasonable is the 'Reasonable' Royalty Rate? Damage Rules and Probabilistic Intellectual Property Rights, August 2006

1779 Ludger Woessmann, Efficiency and Equity of European Education and Training Policies, August 2006

1780 Gregory Ponthiere, Growth, Longevity and Public Policy, August 2006

1781 Laszlo Goerke, Corporate and Personal Income Tax Declarations, August 2006

1782 Florian Englmaier, Pablo Guillén, Loreto Llorente, Sander Onderstal and Rupert Sausgruber, The Chopstick Auction: A Study of the Exposure Problem in Multi-Unit Auctions, August 2006

1783 Adam S. Posen and Daniel Popov Gould, Has EMU had any Impact on the Degree of Wage Restraint?, August 2006 
1784 Paolo M. Panteghini, A Simple Explanation for the Unfavorable Tax Treatment of Investment Costs, August 2006

1785 Alan J. Auerbach, Why have Corporate Tax Revenues Declined? Another Look, August 2006

1786 Hideshi Itoh and Hodaka Morita, Formal Contracts, Relational Contracts, and the Holdup Problem, August 2006

1787 Rafael Lalive and Alejandra Cattaneo, Social Interactions and Schooling Decisions, August 2006

1788 George Kapetanios, M. Hashem Pesaran and Takashi Yamagata, Panels with Nonstationary Multifactor Error Structures, August 2006

1789 Torben M. Andersen, Increasing Longevity and Social Security Reforms, August 2006

1790 John Whalley, Recent Regional Agreements: Why so many, why so much Variance in Form, why Coming so fast, and where are they Headed?, August 2006

1791 Sebastian G. Kessing and Kai A. Konrad, Time Consistency and Bureaucratic Budget Competition, August 2006

1792 Bertil Holmlund, Qian Liu and Oskar Nordström Skans, Mind the Gap? Estimating the Effects of Postponing Higher Education, August 2006

1793 Peter Birch Sørensen, Can Capital Income Taxes Survive? And Should They?, August 2006

1794 Michael Kosfeld, Akira Okada and Arno Riedl, Institution Formation in Public Goods Games, September 2006

1795 Marcel Gérard, Reforming the Taxation of Multijurisdictional Enterprises in Europe, a Tentative Appraisal, September 2006

1796 Louis Eeckhoudt, Béatrice Rey and Harris Schlesinger, A Good Sign for Multivariate Risk Taking, September 2006

1797 Dominique M. Gross and Nicolas Schmitt, Why do Low- and High-Skill Workers Migrate? Flow Evidence from France, September 2006

1798 Dan Bernhardt, Stefan Krasa and Mattias Polborn, Political Polarization and the Electoral Effects of Media Bias, September 2006

1799 Pierre Pestieau and Motohiro Sato, Estate Taxation with Both Accidental and Planned Bequests, September 2006

1800 Øystein Foros and Hans Jarle Kind, Do Slotting Allowances Harm Retail Competition?, September 2006 
1801 Tobias Lindhe and Jan Södersten, The Equity Trap, the Cost of Capital and the Firm's Growth Path, September 2006

1802 Wolfgang Buchholz, Richard Cornes and Wolfgang Peters, Existence, Uniqueness and Some Comparative Statics for Ratio- and Lindahl Equilibria: New Wine in Old Bottles, September 2006

1803 Jan Schnellenbach, Lars P. Feld and Christoph Schaltegger, The Impact of Referendums on the Centralisation of Public Goods Provision: A Political Economy Approach, September 2006

1804 David-Jan Jansen and Jakob de Haan, Does ECB Communication Help in Predicting its Interest Rate Decisions?, September 2006

1805 Jerome L. Stein, United States Current Account Deficits: A Stochastic Optimal Control Analysis, September 2006

1806 Friedrich Schneider, Shadow Economies and Corruption all over the World: What do we really Know?, September 2006

1807 Joerg Lingens and Klaus Waelde, Pareto-Improving Unemployment Policies, September 2006

1808 Axel Dreher, Jan-Egbert Sturm and James Raymond Vreeland, Does Membership on the UN Security Council Influence IMF Decisions? Evidence from Panel Data, September 2006

1809 Prabir De, Regional Trade in Northeast Asia: Why do Trade Costs Matter?, September 2006

1810 Antonis Adam and Thomas Moutos, A Politico-Economic Analysis of Minimum Wages and Wage Subsidies, September 2006

1811 Guglielmo Maria Caporale and Christoph Hanck, Cointegration Tests of PPP: Do they also Exhibit Erratic Behaviour?, September 2006

1812 Robert S. Chirinko and Hisham Foad, Noise vs. News in Equity Returns, September 2006

1813 Oliver Huelsewig, Eric Mayer and Timo Wollmershaeuser, Bank Behavior and the Cost Channel of Monetary Transmission, September 2006 